Review

\title{
Progress in the Synthesis of Bifunctionalized Polyhedral Oligomeric Silsesquioxane
}

\author{
Mingyue Wang ${ }^{1}$, Hong Chi ${ }^{1}{ }^{1} * \mathbb{D}$, Joshy K.S. ${ }^{1}$ and Fuke Wang ${ }^{2, *}$ \\ 1 Shandong Provincial Key Laboratory of Molecular Engineering, School of Chemistry and Pharmaceutical \\ Engineering, Qilu University of Technology (Shandong Academy of Sciences), Jinan 250353, China; \\ Silvia9607@163.com (M.W.); joshyk.s@gmail.com (J.K.S.) \\ 2 Institute of Materials Research and Engineering, A*STAR (Agency for Science, Technology and Research), \\ Fusionopolis Way, Innovis, \#08-03, Singapore 138634, Singapore \\ * Correspondence: chihong@qlu.edu.cn (H.C.); wangf@imre.a-star.edu.sg (F.W.)
}

Received: 14 November 2019; Accepted: 11 December 2019; Published: 14 December 2019

check for updates

\begin{abstract}
Polyhedral oligomeric silsesquioxane (POSS) has been considered as one of the most promising nanofillers in academic and industrial research due to its unique multifunctional nanostructure, easy functionalization, hybrid nature, and high processability. The progress of POSS has been extensive, particularly applications based on single- or multiple-armed POSS. In polymer hybrids, in order to enhance the properties, bifunctional POSS has been incorporated into the backbone chain of the polymer. This review summarizes recent developments in the synthesis, modification, and application of bifunctional POSS-containing composite materials. This includes amino-POSS, hydroxyl-POSS, aromatic ring-POSS, ether-POSS, and vinyl groups-POSS and their applications, exemplified by polyurethanes (PUs) and polyimides (PIs). In addition, the review highlights the enhancement of thermal, mechanical, and optical properties of the composites.
\end{abstract}

Keywords: polymer composite; bifunctional POSS; asymmetry; functionalization

\section{Introduction}

In recent years, inorganic-organic hybrid materials with carbon nanotubes [1-5], graphene [6-9], organosilicons [10-12], metal oxides [13,14], and natural polymers [15-17] have attracted considerable attention because of their distinctive properties. Among these, the incorporation of polyhedral oligomeric silsesquioxane (POSS) has attracted attention because of its unique frame structure and the resulting chemical and physical properties, including high thermal properties [18-20], lower crystallinity [21], mechanical properties [22], oxidation resistance, and very good dielectric properties [23,24]. Hence, it has been widely used in preparing polymer hybrids and polymer composites in many areas, including optics [25], electronics, ionic liquids [26], mechanics [27], energy [28], environment [29], biology [30], smart coatings [31,32], fuel [33], solar cells [34], catalysts [35,36], sensors [37-39], light-emitting devices [40], and medicine [41-44].

With a silicon core and surrounding organic functional groups, POSS itself is a hybrid material at the molecular level. It is composed of a cubic polyhedron cage surrounded by multiple silicon oxygen rings. The substituents on the Si atom at the vertex of the POSS polyhedron can be a variety of reactive or nonreactive groups. The desired properties can be obtained by alternating the types of organic groups on the Si endpoint that determines whether POSS is reactive or functionalized $[45,46]$. POSS enhances the mechanical properties of polymers (e.g., modulus, strength, hardness) and decreases heat evolution and melt viscosity $[17,47]$. POSS increased the chain rigidity of polymers, and as a result, the glass transition temperatures $\left(T_{\mathrm{g}}\right)$ were greatly enhanced. High-molecular-weight copolymers will be obtained by incorporating POSS moieties, which will result in improved mechanical properties. Due 
to this excellent property, these polymeric materials have found wide application in both academic and industrial fields. For example, hybrid POSS/polyurethane (PU) material has been applied for the construction of synthetic heart valve leaflets [48] and aortic stent grafts in medicine [49].

The classic eight-armed POSS-containing hybrids normally form cross-linked networks, hence they exhibit poor solubility in most organic solvents. On the other hand, single-armed POSS macromeres used as pendent [50-52] or cross-linking sites will not affect the main chains or overall properties of POSS-containing polymers. Bifunctional POSSs (B-POSSs) are emerging silsesquioxanes that are usually incorporated into the backbone of polymers, leading to the occurrence of several new functions, such as nonflammability, oxidative resistance, and excellent dielectric properties [53-56]. When B-POSSs are introduced into the main chain of a polymer, the improved performance of the polymer is mainly due to the altered motion of the polymer chains. Thus, B-POSS has received attention because of its fascinating properties, such as good thermal and mechanical properties, excellent transparency, and excellent flexibility [57-59]. For example, Wei et al. [60] successfully synthesized a B-POSS through a click reaction between 3,13-diazidopropyloctaphenyl double-decker silsesquioxane (DDSQ; compound 18) and $\alpha, \omega$-dialkynyl-terminated oligoethylenes. This B-POSS showed high thermal stability, high hydrophobicity, and low surface energy. It also showed many excellent properties, which makes it a promising candidate for flexible substrates and polymer electronics. For example, B-POSS itself is a hydrophobic material; thus, it is not inclined to adhere to metals. Mohammod et al. [55] reported the surface modification of B-POSS by the incorporation of silanol groups $(\mathrm{Si}-\mathrm{OH})$ in the film. The surface of B-POSS film changed from hydrophobic to hydrophilic by irradiation with deep ultraviolet (UV) radiation. The deep UV radiation cleaved the Si-O-Si cage of silicones. Silver (Ag) micropatterns on the surface of B-POSS film were also fabricated by the deep UV irradiation process. The obtained Ag micropatterns exhibited excellent adhesion on the modified surface.

The composites usually show many interesting properties, such as amphiphilic [61], thermal [62], and optic properties [63], and also form complexes using coordination chemistry [64]. The incorporation of B-POSS into the main chains of a polymer results in significant lowering of the dielectric constant. This is because B-POSS has an inert inorganic silicon framework [65]. In addition, B-POSS-based materials possess desirable chemical and physical properties due to their structural and property variability, which is tuned by the modulation of functional groups. Sodkhomkhum et al. [66] reported the synthesis of poly(siloxane/B-POSS) via a polycondensation reaction between chlorides containing B-POSS and hexamethyltrisiloxane with high $T_{\mathrm{g}}$ and transparency. Iso-butyl end-capped B-POSS reported by Groch et al. [67] showed enhanced solubility compared with methyl end-capped B-POSS. Thermal properties investigated by thermogravimetric analysis (TGA) showed that the polymers had exceptionally high thermal degradation temperature $\left(T_{\mathrm{d}}\right)$ in the range of $470-530{ }^{\circ} \mathrm{C}$ whether in nitrogen or air atmosphere. About $80 \%$ residual weight of the polymers was found in nitrogen atmosphere at $760^{\circ} \mathrm{C}$.

Due to the promising applications of B-POSS, this review focuses on its synthesis and functionalization methods. The applications and properties of polymers containing POSS will also be introduced. Finally, we suggest some prospects for POSS from our own perspective.

\section{Functional Methods of B-POSS}

Figure 1 shows the schemes of various synthetic possibilities of B-POSS. Generally, B-POSS is synthesized through reactions between raw materials such as phenyltrimethoxysilan, isopropanol, sodium hydroxide, and methylvinyl dichlorosilane or methyldichlorosilane. B-POSS has been obtained by involving the synthesis of 3,13-dihydrooctaphenyl B-POSS (2) and bifunctional POSS. During the synthesis of B-POSS, Karstedt catalyst was used and tetrahydrofuran (THF) toluene or isopropanol were employed as solvent. The obtained B-POSS was washed with methanol or hexane and characterized by ${ }^{1} \mathrm{H}-\mathrm{NMR},{ }^{29} \mathrm{Si}-\mathrm{NMR}$, (Fourier transform infrared spectroscopy) (FT-IR ) analysis. 


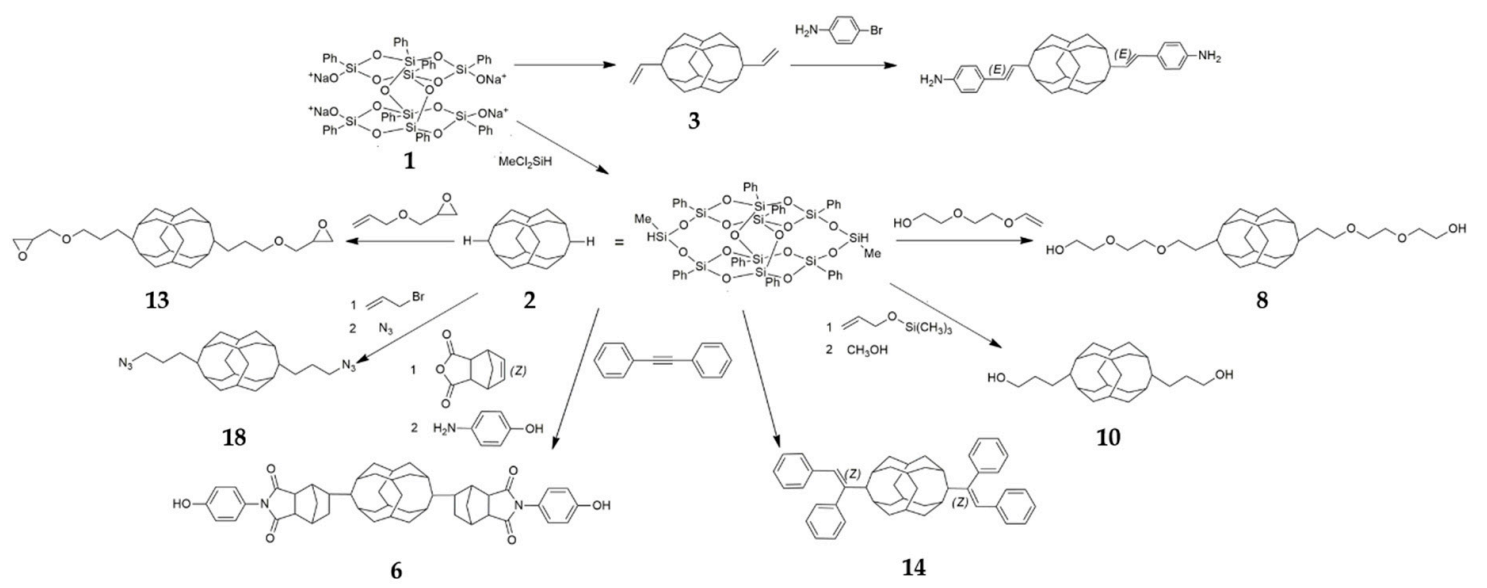

Figure 1. Schematic illustration of reaction types of bifunctional polyhedral oligomeric silsesquioxanes (B-POSSs) including octaphenyldicycloocatasiloxane tetrasodium Silanolate (1), 3,13-dihydrooctaphenyl B-POSS (2), 3,13-divinyl B-POSS (3), para-aminophenol anhydride B-POSS (6), di(ethylene glycol) POSS (8), 3,13-Dihydroxypropyloctaphenyl B-POSS (10), 3,13-diglycidyloxypropyloctaphenyl B-POSS (13), 3,13-diphenylethenyl B-POSS (14), 3,13-diazidopropyloctaphenyl B-POSS (18). Numbers denote compounds discussed in the paper.

\subsection{Amino-Functionalized POSS}

Liu et al. synthesized diamine-modified POSS (4) by means of a Heck reaction, as shown in Figure 2 [68]. An ocatasiloxane tetrasodium silanolate (denoted $\mathrm{Na}_{4} \mathrm{O}_{14} \mathrm{Si}_{8}\left(\mathrm{C}_{6} \mathrm{H}_{5}\right)_{8}$ ) (compound 1) was first obtained through the hydrolysis of a phenyltrimethoxysilane precusor in isopropanol by using the same procedure as Kakimoto et al. [69]. Phenyltrimethoxysilane, isopropanol, and sodium hydroxide were used as the precursor, solvent, and catalyst, respectively. Diamine-modified POSS was obtained through the reaction between 3,13-divinyl B-POSS (3) and 4-bromoaniline with palladium catalyst (Figure 2), with a yield of $91 \%$. The structures of compounds 3 and 4 were verified by ${ }^{1} \mathrm{H}-\mathrm{NMR}$. Compared with one-armed POSS, compound 4 can be adopted to synthesize polymer hybrids containing B-POSS in the backbone, including polyamide (PA), polyurethane (PU), and polyimide (PI), through step polymerization, where the activity of the amine functional group is of prime concern.

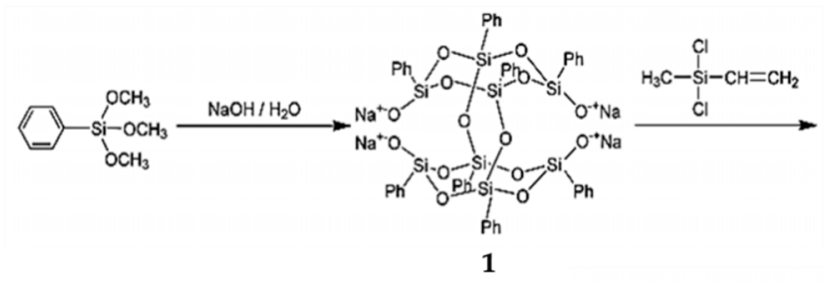

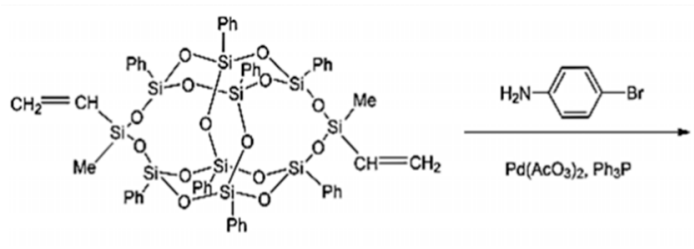

3

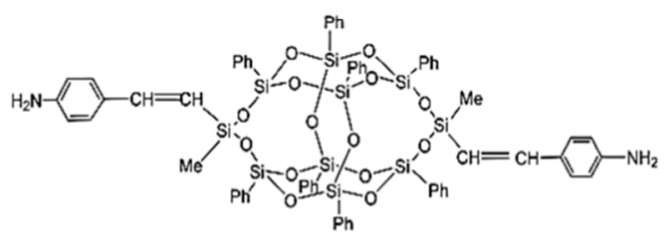

4

Figure 2. Synthesis of 3,13-dianilino B-POSS (4). (Reprinted with permission from Liu et al. [68]. Copyright 2016 Royal Society of Chemistry).

Based on compound 4, Liu et al. [70] prepared polybenzoxazine-B-POSS (PBZ-B-POSS) copolymers, as shown in Figure 3. For this, compound 4 was introduced into main chains of polybenzoxazines (PBZs) by reaction with 4,4-diaminodiphenylmethane (DDM), 4,4'-dihydroxyldiphenylisopropane, and formaldehyde. Compared to neat PBZ, the hybrid copolymers exhibited enhanced surface 
hydrophobicity with increased content of B-POSS. The contact angle of PBZ-B-POSS copolymers was significantly higher than that of neat PBZ $\left(99.6^{\circ}\right)$. PBZ-B-POSS thermoset copolymers can be easily obtained by thermally activated ring-opening polymerization.
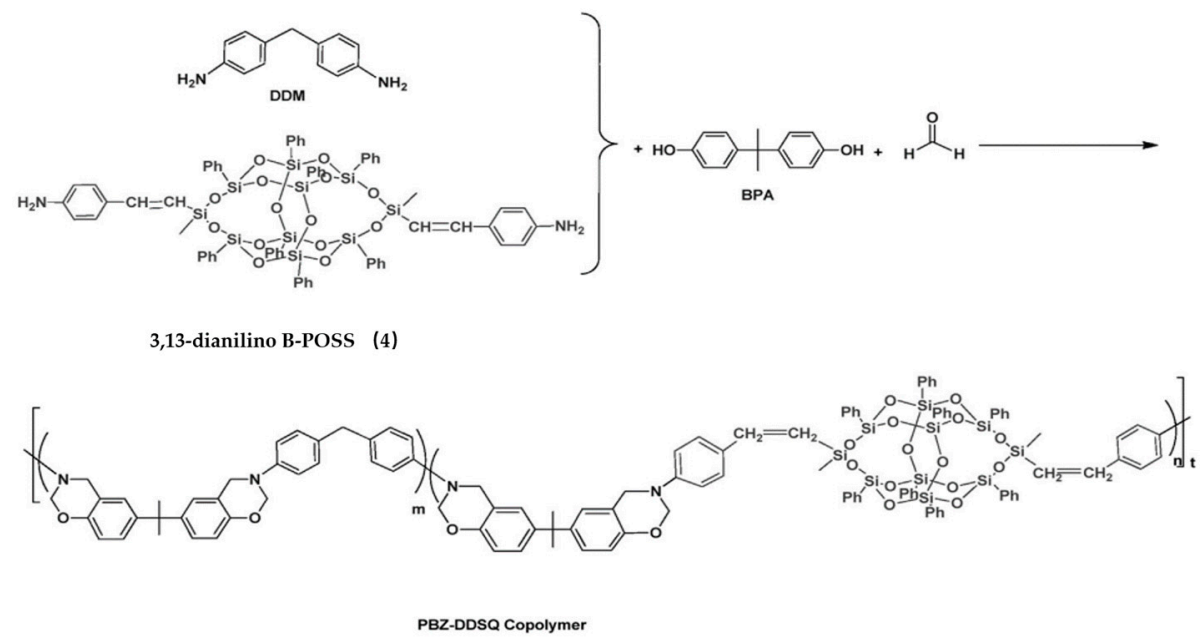

Figure 3. Synthesis of organic-inorganic polybenzoxazine-B-POSS (PBZ-B-POSS) copolymers based on compound 4. (Reprinted with permission from Liu et al. [70]. Copyright 2017 Elsevier).

Based on compound 2, Wu et al. [71] reported the synthesis of aromatic tetracarboxylic dianhydride modified B-POSS via the reaction between 3,13-dianilino B-POSS (4) and pyromellitic dianhydride. The hybrid exhibited enhanced solubility, $5 \%$ weight loss $\left(T_{5} \%\right.$ at $570{ }^{\circ} \mathrm{C}$ in nitrogen atmosphere, and a high $T_{\mathrm{g}}$ of $300^{\circ} \mathrm{C}$. On the other hand, tetracarboxylic dianhydride modified B-POSS can be synthesized before the modification of diamine groups, as exemplified by Wu et al. [72]. Double-decker-shaped silsesquioxane dianhydride was synthesized before further reaction with 4,4-oxydianiline. ${ }^{29} \mathrm{Si}-\mathrm{NMR}$ confirmed their structure by the appearance of peaks at intensity values of $-21.8,-78.3$, and $-78.9 \mathrm{ppm}$.

When 4,4-oxydianiline is replaced by p-aminophenol or o-aminophenol, hydroxyl group modified B-POSS can be formed, as reported by Chen et al. (Figure 4). [73] First, compound 5 was reacted with p-aminophenol or o-aminophenol to form the para-aminophenol anhydride B-POSS (B-POSS-ND- $p$-OH) (6) and ortho-aminophenol anhydride B-POSS (B-POSS-ND-o-OH) (7), as shown in Figure 4. The influence of the substitution position of the B-POSS on the thermal stability and thermal behavior of these (benzoxazine) (BZ) monomers was well investigated. The thermal investigation of B-POSS-BZ monomers proved that the incorporation of B-POSS enhanced their resistance to the degradation of the hybrid monomers. The ortho-substitution of the aminophenol units resulted in lower thermal stability than the para-substitution of the aminophenol units.

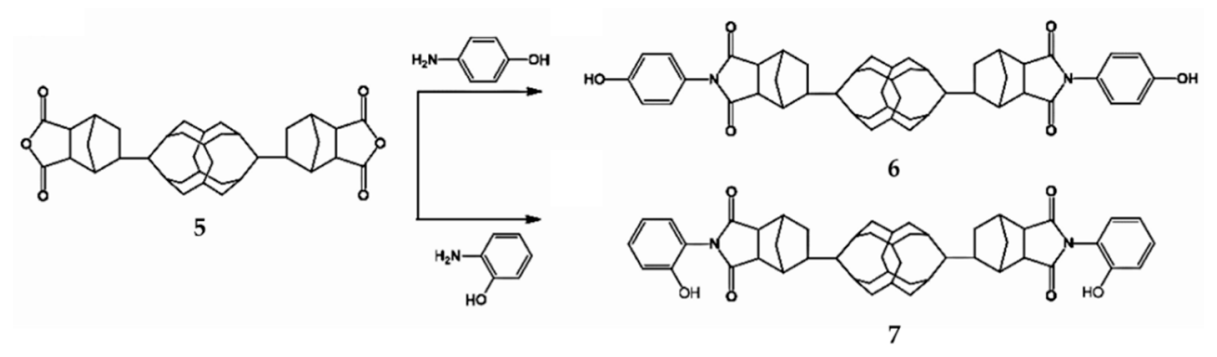

Figure 4. Synthesis of compounds B-POSS-ND-p-OH (6) and B-POSS-ND-o-OH (7) from 5. (Reprinted with permission from Chen et al. [73]. Copyright 2018 American Chemical Society).

\subsection{Hydroxyl Functionalized POSS}

Due to the strong aggregation tendency of the super-hydrophobic POSS moiety [74], we reviewed the mechanism of amphiphilic hybrid POSS copolymer in self-assembly, in which POSS can 
effectively control the motion of the polymer chain [75]. Kucuk et al. reported the preparation of the first (Langmuir-Blodgett film) (L-B film) containing B-POSS with a well-defined structure [76]. Amphiphilic two- and four-armed di(ethylene glycol) POSS (2OH-B-POSS) (8) and 4OH-B-POSS (9) were synthesized. 2OH-B-POSS was formed by the reaction between 2H-B-POSS and a 1.3-fold excess amount of di(ethylene glycol) vinyl ether by means of a direct hydrosilylation reaction (Figure 5). Similarly, 4OH-B-POSS was obtained, and the structure was confirmed by ${ }^{1} \mathrm{H}-\mathrm{NMR}$. Through surface pressure-area $(\pi-\mathrm{A})$ isotherms and Brewster angle microscopy, the amphiphilic B-POSS monolayer at the air-water interface was observed.
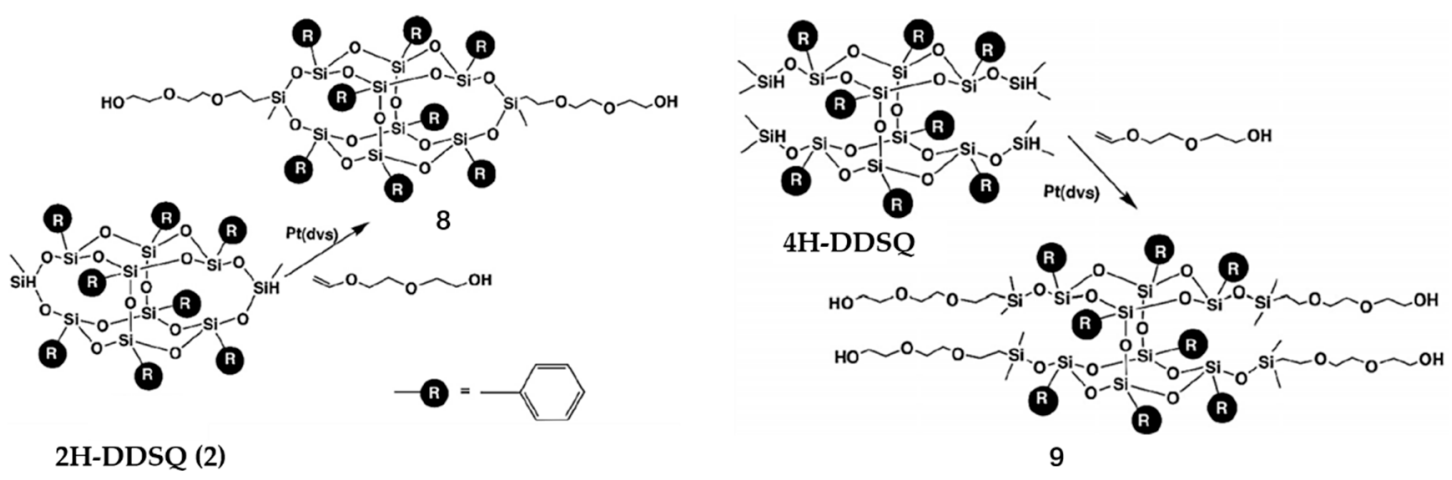

Figure 5. Synthesis of 4OH-B-POSS (9) of four hydrogen double-decker silsesquioxane (4H-DDSQ) with di(ethylene glycol) vinyl ether via hydrosilylation. (Reproduced with permission from Kucuk et al. [76]. Copyright 2011 Elsevier).

To further probe the hydrogen bonding effect on the monolayer properties, they also synthesized amphiphilic B-POSS with core-corona amphiphile full name 2-di(ethylene glycol) urethane B-POSS (2DEGNH-B-POSS) [77]. Ethyl isocyanate and 2-di(ethylene glycol) B-POSS (2DEG-B-POSS) were used as raw materials to fabricate $2 \mathrm{DEGNH}-\mathrm{B}-\mathrm{POSS}$. The structure was confirmed via ${ }^{1} \mathrm{H}-\mathrm{NMR}$ and FT-IR. The 2DEGNH-B-POSS with a urethane group at the end exhibited a strong hydrogen bond interaction in the 2DEGNH-B-POSS rod-like assemblies. A uniform liquid-like monolayer was formed by the mixture of 2DEGNH-B-POSS and full name 2DEG-B-POSS (1:1 molar ratio). Monolayer properties could be improved because of the hydrogen bonds between the urethane groups in 2DEGNH-B-POSS and the hydroxyl groups in 2DEG-B-POSS, which guaranteed the successful separation of L-B film.

3,13-Dihydroxypropyloctaphenyl B-POSS (10) was synthesized by Wei et al. [78]. First, 3,13di(trimethylsilyl)oxypropyloctaphenyl B-POSS was obtained by means of a hydrosilylation reaction between B-POSS and allyloxytrimethylsilane. Then, compound $\mathbf{1 1}$ was obtained through a deprotection reaction of 3,13-di(trimethylsilyl)oxypropyloctaphenyl B-POSS (Figure 6). ${ }^{1} \mathrm{H}-\mathrm{NMR}$ confirmed their structure by the appearance of a $\mathrm{CH}_{3}-\mathrm{Si}$ group at $0.38 \mathrm{ppm}, \mathrm{Si}-\mathrm{H}$ group at $4.98 \mathrm{ppm}$, benzene rings at 7.14-7.50 ppm, and $-\mathrm{OSiCH}_{3} \mathrm{CH}_{2} \mathrm{CH}_{2} \mathrm{CH}_{2} \mathrm{OH}$ group at $0.31 \mathrm{ppm}$. Then, compound 10 was used as a chain extender to produce linear hybrid PUs with B-POSS in the backbone. These organic-inorganic linear PUs showed enhanced surface hydrophobicity. It was also noted that the $T_{\mathrm{g}}$ values increased with the increased content of B-POSS. 


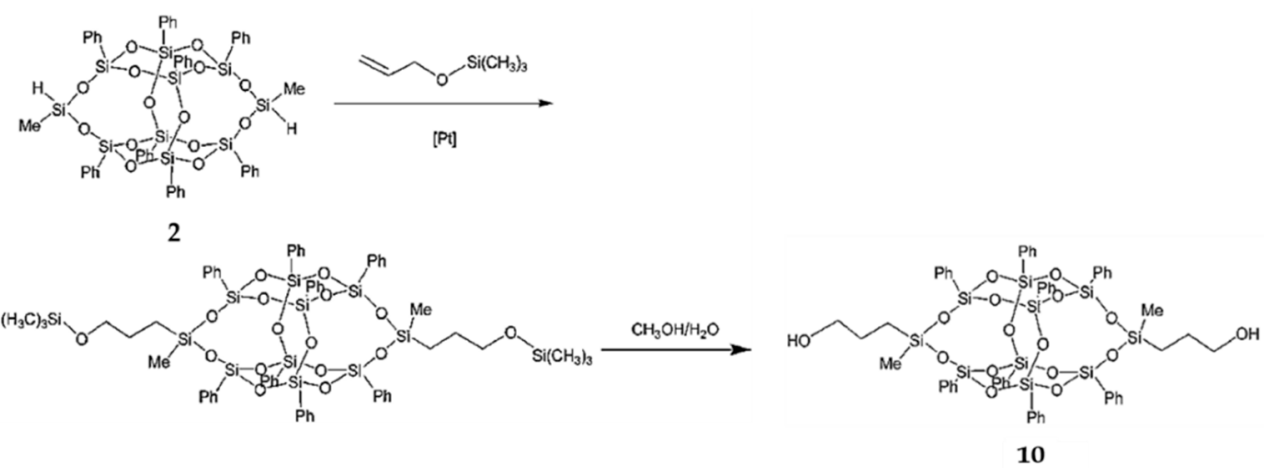

Figure 6. Synthesis of 3,13-dihydroxylpropyloctaphenyl B-POSS (10). (Reproduced with permission from Wei et al. [78]. Copyright 2012, Royal Society of Chemistry).

Wen et al. [79] synthesized epoxy soybean oil-based polyurethanes modified by 3,13dimethyhydroxysilyl double-decker phenylsilsesquioxane (B-POSS(Me)OH). B-POSS(Me)OH was directly obtained by the reaction between compound 1 and methyltrichlorosilane. ${ }^{1} \mathrm{HNMR}$ and MALDI-TOF-MS confirmed the successful synthesis of B-POSS(Me)OH. TGA was applied to investigate the thermal properties of hybrid polyurethanes. At high temperature, the thermal stability and flame resistance of the hybrids were significantly improved because of the silicon dioxide generated from the oxidation of B-POSS(Me)OH wrapping on the surface. Differential scanning calorimetry (DSC) showed that the $T_{\mathrm{g}}$ of the hybrid polyurethane exhibited a parabolic linear relation with the increased B-POSS(Me)OH content. By incorporating different contents of B-POSS(Me)OH, the mechanical property of hybrid polyurethane varied, and the amount exceeded $4.6 \mathrm{wt} \%$, and the tensile strength started to decrease.

Han et al. [80] reported a variety of Janus-type regioisomeric B-POSSs functionalized by hydroxyl groups, which were synthesized through thiol-ene "click" chemistry (Figure 7). ${ }^{1} \mathrm{H}$ NMR and ${ }^{13} \mathrm{C}$ NMR were successfully applied to differentiate and study a class of mixed octakis-adduct regioisomers with various surface positional functional groups. Due to the existance of equivalent vinyl groups, the para-substitutional product $p-\mathrm{T}_{8} \mathrm{~V}_{6}(\mathrm{OH})_{2}$ only exhibited one set of strongly coupled, second-order spectra of an $\mathrm{ABC}$ spin system by ${ }^{1} \mathrm{H}$ NMR. Tiny differences in the chemical shifts beween experimental and simulated spectra were found in $m$ - and $o-\mathrm{T}_{8} \mathrm{~V}_{6}(\mathrm{OH})_{2}$ (meta or ortho-substitutional product which obtained by the $\mathrm{V}_{8} \mathrm{~T}_{8}$ showed in the Figure 7). The spectral pattern presented a group of signals from each individual subset of vinyl resonance signals. The ${ }^{13} \mathrm{C}$ NMR spectra of $p-, m-$, and $o-\mathrm{T}_{8} \mathrm{~V}_{6}(\mathrm{OH})_{2}$ were also classified according to the differences between them. 

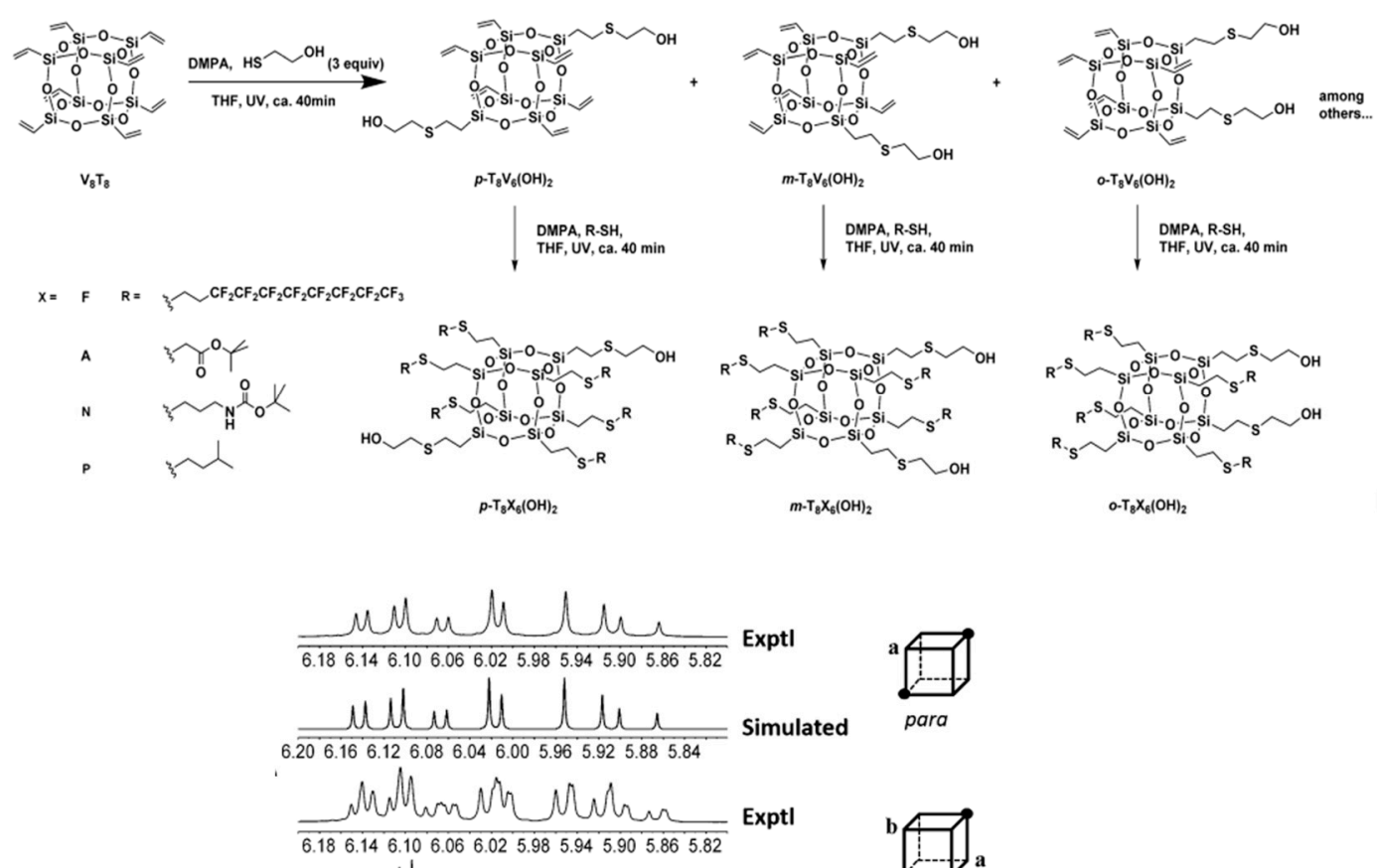

(B)
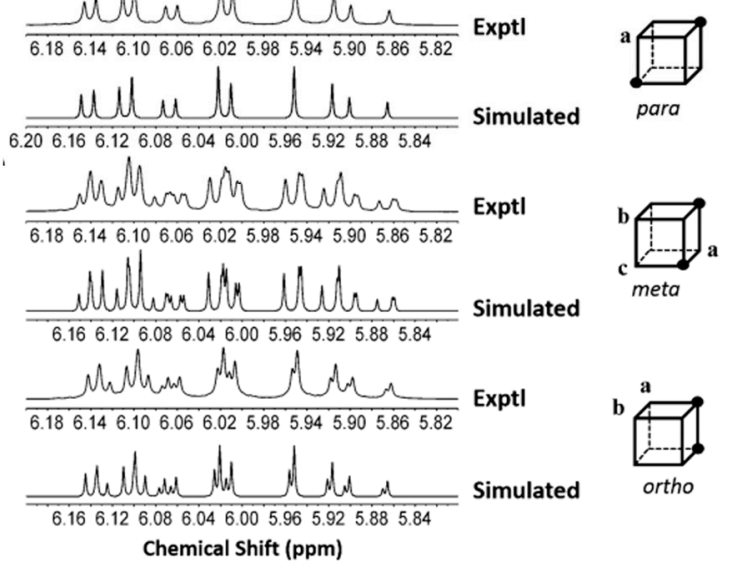

Figure 7. (A) Synthesis of para-, meta-, and ortho- $\mathrm{T}_{8} \mathrm{X}_{6}(\mathrm{OH})_{2}(\mathrm{X}=\mathrm{V}, \mathrm{F}, \mathrm{A}, \mathrm{N}$, or $\mathrm{P})$ with hydroxyl groups. (B) Experimental and simulated ${ }^{1} \mathrm{H}$ NMR spectra of the products. Letters indicate chemically inequivalent vinyl groups on the POSS cage. (Reprinted with permission from Han et al. [80]. Copyright 2016 John Wiley and Sons).

\subsection{Aromatic Ring Functionalized POSS}

To synthesize high-performance polymers, POSSs are often functionalized with aromatic groups [81-84]. Seino et al. [69] reported that the reaction between B-POSS and diynes resulted in the formation of linear polymers via hydrosilylation polymerization. Compound $\mathbf{1 1}$ was formed quantitatively through the reaction of compound 2 with diphenylacetylene (Figure 8). The polymerization of B-POSS with diynes was obtained via hydrosilylation, as shown in Figure 8. Chemical structures were confirmed by ${ }^{1} \mathrm{H}-\mathrm{NMR}$ spectroscopy; the characteristic peaks of B-POSS were methyl groups ranging from 0.22 to $0.38 \mathrm{ppm}$, and the characteristic peaks of the phenylene group signals appeared from 6.41 to $7.59 \mathrm{ppm}$.

Benzocyclobutene (BCB) is a moiety that can be introduced into polymers and oligomers due to its high refractive index, stable air and moisture exposure, low dielectric constant, and excellent thermal and mechanical properties. A series of benzocyclobutene-functional B-POSSs (2BCB-B-POSS and 4BCB-B-POSS) were synthesized by Hu et al. [85]. After curing at above $200^{\circ} \mathrm{C}$, the hybrid resins were converted into highly cross-linked polymers with enhanced thermal stability and optical and electrical properties via Diels-Alder reaction. Compared with resin cured without B-POSS, this BCB-B-POSS showed better performance in terms of low water abosorption, low heat transfer, low dielectric constant, and higher (light emitting diode) (LED) luminous efficiency. A new type of bifunctional phenolic B-POSS (B-POSS-BP) was synthesized with allylamine and $\mathrm{CH}_{2} \mathrm{O}$ via Mannich condensation to form a bis-allyl benzoxazine B-POSS derivative (B-POSS-BZ) by Liao et al. [86]. The B-POSS was critical in 
preparing thermally stable, optically transparent, and mechanically flexible polybenzoxazine polymers after the hydrosilylation of B-POSS-BZ with polydimethylsiloxane (PDMS).

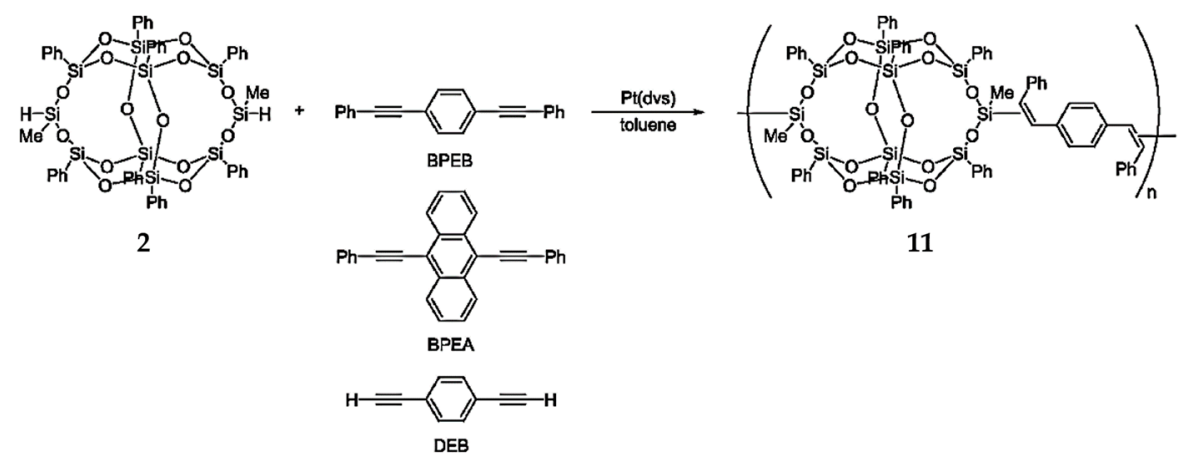

Figure 8. Hydrosilylation polymerization of B-POSS with diynes. (Reproduced with permission from Seino et al. [69]. Copyright 2006 American Chemical Society).

\subsection{Divinyl Functionalized B-POSS}

From the synthetic point of view, divinyl substituted B-POSS is important in free radical polymerization and silylative coupling. Mituła et al. synthesized dialkenyl-substituted B-POSS, including allyl, hex-5-enyl-, and dec-9-enyl-B-POSS, by condensation and hydrosilylation processes (Figure 9) [87]. First, dichloro(alkenyl)methylsilane was obtained by the reaction between dichloromethylsilane and 1,9-decadiene under the $\left[\mathrm{Pt}_{2}(\mathrm{dvds})_{3}\right]$ catalyst. Then, B-POSS-2Si-decenyl was obtained by the condensation reaction between B-POSS-4OH and dichloro(dec-9-enyl)methylsilane under triethylamine $\left(\mathrm{R}_{3} \mathrm{~N}\right)$ and THF. B-POSS-2-Si-Allyl $(n=1)$, B-POSS-2-Si-hexenyl $(n=4)$, and B-POSS-OH $(n=8)$ were also obtained by the same reaction. Walczak et al. [88] also reported the synthesis of a series of B-POSS functionalized highly $\pi$-conjugated ethylarenes and analogous hybrid materials. The existance of compound 2 with both cis- and trans-isomers was verified by ${ }^{29} \mathrm{Si} \mathrm{NMR}$. The appearance of $18.35,78.51$, and $79.46 \mathrm{ppm}$ peaks and $18.35,78.51,79.40$, and $79.49 \mathrm{ppm}$ peaks was attributed to the trans- and cis-isomers, respectively. This new B-POSS compound was reacted with styryl- and bis(styryl)arenes via hydrosilylation reaction, leading to the formation of ethyl bridged molecular and macromolecular hybrid systems.

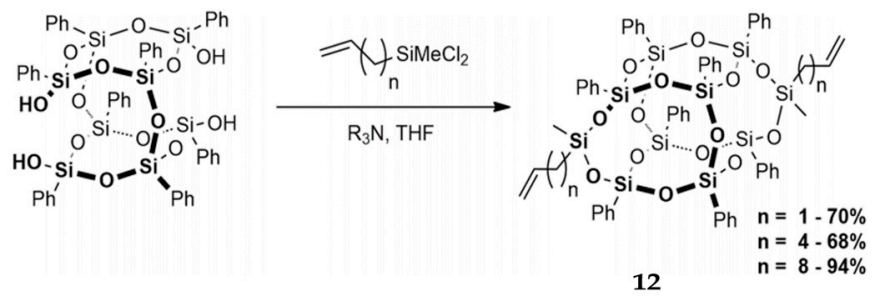

Figure 9. Synthesis of dialkenylfunctional B-POSS (12) via condensation reaction. (Reprinted with permission from Mituła et al. [87]. Copyright 2017 Creative Commons CC BY license).

Along with silylative coupling, cross-metathesis provides efficient and complementary synthetic routes, leading to B-POSS hybrids of great practical importance. Zak et al. [89] produced a series of functionalized dialkenyl silsesquioxanes. Two types of transititon metal-catalyzed reactions, highly stereoselective silylative coupling (SC) and cross-metathesis (CM), of divinyl substituted B-POSS (B-POSS-2SiVi) with substituted styrenes and other olefins were used for the synthesis, resulting in the formation of E isomer quantitatively.

After that, silylative coupling and metathetic copolymerization (ADMET) were further used to synthesize a new class of vinylene-arylene and B-POSS copolymers in another work [90]. Different arenes were polymerized in order to compare their thermal and mechanical properties. TGA proved 
high thermal resistance over $550^{\circ} \mathrm{C}$, depending on the B-POSS content. Gel permeation chromatography (GPC) measurements confirmed that the average molecular weight $\left(M_{\mathrm{W}}\right)$ of copolymers improved with the elongation of reaction time, which was possibly due to the steric hindrance.

It was found that the activity of the catalyst was affected by the feeding ratio of B-POSS in the copolymerization. Groch et al. [91] synthesized copolymers of ethylene with divinyl substituted B-POSS by coordinative copolymerization under the catalyst of metallocene and bis(phenoxy-imine). The B-POSS content varied in the range of $0.93-11.53 \mathrm{wt} \%$ to optimize and obtain the relation between compositions and the structural properties of copolymers. Different products were obtained depending on the different B-POSS content, pressure of ethylene, and time of reaction. Results indicated that with increased feeding concentration of B-POSS, the activity of metallocene catalyst was found to initially increase and then gradually decrease over a critical value.

\subsection{Asymmetric Functionalization of B-POSS}

Incorporating B-POSS in the polymer chain provides a more effective retardation of the chain motion of the linear polymer, which might allow higher effectiveness in property modulation. However, it is noteworthy that B-POSS bridging different segments or chains on each side may offer an interesting new class of materials.

Vogelsang et al. [92] reported a method to obtain asymmetric side-capped B-POSS by using a combination of dichloro- and trichlorosilane capping agents (Figure 10). A mixture of symmetric and asymmetric B-POSSs was obtained by the reaction between B-POSS $(\mathrm{OH})_{4}$ and $\left(\mathrm{CH}_{3}\right)(\mathrm{R}) \mathrm{SiCl}_{2}$, $\left(\mathrm{CH}_{3}\right) \mathrm{SiCl}_{3}$, as shown in Figure 10. To obtain $\mathrm{AB}$ type, liquid chromatography (LC) was considered as an effective separation technique and was employed to obtain compound 15 (AB) with asymmetric functionality. However, significant symmetric byproduct waste would be generated and it required differences in polarity between the byproducts and the desired asymmetric material to be effectively separated.

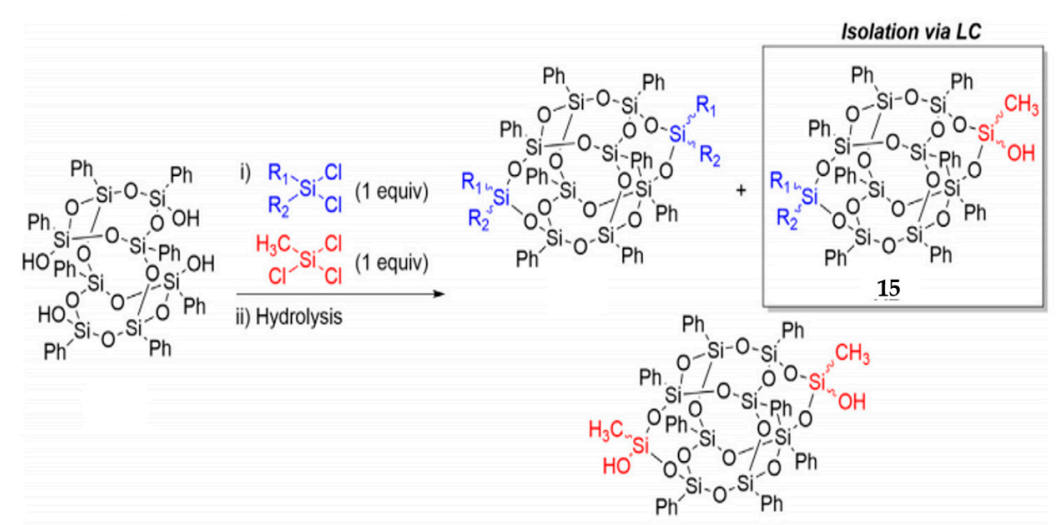

Figure 10. Asymmetric side-capped B-POSS by using a combination of dichloro- and trichlorosilane capping agents. (Reprinted with permission from Vogelsang et al. [92]. Copyright 2018 Elsevier).

Based on Vogelsang's work, Barry et al. reported a more effective route to synthesize asymmetric functional B-POSS (16) by the selective protection of silanols with boronic acid (Figure 11) [93]. Such an active protecting group could protect two silanols simultaneously, and it could be easily introduced and removed without affecting the B-POSS framework. In this way, high recyclable starting tetraol B-POSS was also achieved. 4-Methoxyphenylboronic acid was used because its outstanding methoxy protons gave a high yield ( $98 \%$ ) and simple spectroscopic analysis was allowed. The protocol is general and highly efficient for a wide range of asymmetrically functionalized B-POSSs. 


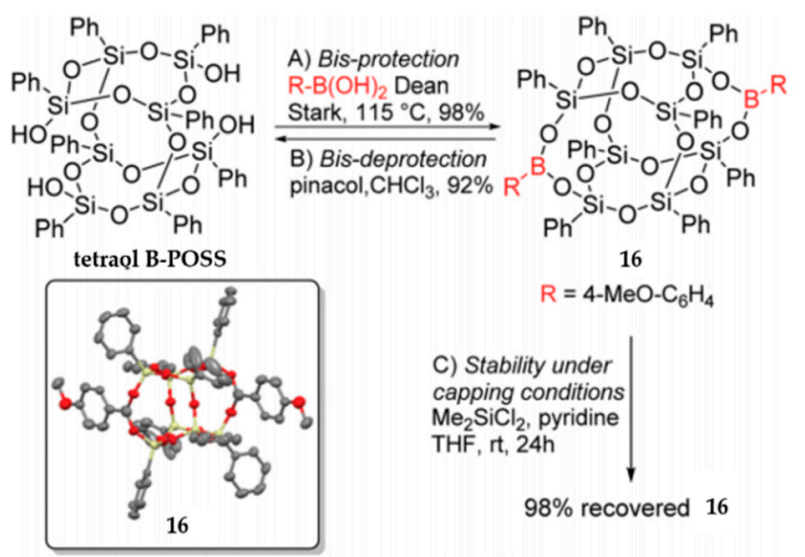

Figure 11. Asymmetric functional B-POSS by the selective protection of silanols with boronic acid. $B$ represents the boron atom and the $\mathrm{R}$ on the boron atom represents $4-\mathrm{Me}-\mathrm{C}_{6} \mathrm{H}_{4}$, which are more clearly to show selective-protected location of the tetraol B-POSS. (Reprinted with permission from Barry et al. [93]. Copyright 2019 Royal Society of Chemistry).

A special catalyst was also explored in the selective synthesis of asymmetric B-POSS. Zak et al. reported ruthenium-N-heterocyclic carbene complexes (formula $\left[\mathrm{RuHCl}(\mathrm{CO})(\mathrm{NHC})\left(\mathrm{PCy}_{3}\right)\right]$ ) as efficient and selective catalysts [94]. The $\left[\mathrm{RuHCl}(\mathrm{CO})(\mathrm{NHC})\left(\mathrm{PCy}_{3}\right)\right]$ complexes were obtained by ligand exchange between tricyclohexylphosphine ( $\mathrm{PCy}_{3}$ ) and $\mathrm{N}$-heterocyclic carbene ( $\mathrm{NHC}$ ). The high catalytic activity exhibited by the new catalyst allowed the bifunctionalization of three divinyl-substituted B-POSS cage compounds in one pot. Tian et al. [95] synthesized a kind of asymmetric functional B-POSS with silyl hydride at one end and two silanol groups at the other end. Here, only one of the two silanol groups coupled with silyl hydride, while the other silanol remained intact owing to steric hindrance. Blanco et al. [96] prepared POSS/PS hybrids by in situ polymerization to compare the effect of symmetry and asymmetry POSSs in terms of thermal property. The asymmetry POSS/PS showed better thermal performance indicated by TG, (differential thermogravimetric) (DTG), and DSC. Tanaka et al. [97] also investigated the thermal and mechanical properties of a series of polymers such as polystyrene (PS), poly (methyl methacrylate) (PMMA), and ethylene-(vinyl acetate) copolymer (EVA), which were incorporated with $5 \mathrm{wt} \%$ POSS. The polymer matrices showed good thermal stability because of the incorporation. The SEM suggested the homogeneous dispersion of POSS. The POSS fillers were found to enhance the hardness of PS, which was confirmed by (dynamic mechanical analysis) (DMA). Hence, obtaining asymmetrical POSS molecules is highly important for dispersion in the polymer matrix.

\subsection{Other Bifunctional POSS}

Chlorine-containing bifunctional POSS (Cl-B-POSS) with excellent optical transparency and hydrophobicity was obtained via the polycondensation reaction of di[(3-chloropropyl)isopropoxysilyl]bridged B-POSS with hexamethyltrisiloxane by Sodkhomkhum et al. [66]. Phosphonic-acid-containing B-POSS (PHOS-B-POSS) (17) was synthesized by Kucuk et al. to prepare proton-conducting electrolyte film [98]. First, four-armed di(ethylene glycol) B-POSS [4DEG-B-POSS] (9) was obtained via hydrosilylation reaction using 4H-B-POSS and di(ethylene glycol) (DEG) vinyl ether, with $\mathrm{Pt}(\mathrm{dvs})$ as catalyst. Then, compound 17 was synthesized through the reaction between compound 9 and (phosphorus oxychloride) $\left(\mathrm{POCl}_{3}\right)$ (Figure 12). ${ }^{1} \mathrm{H}-\mathrm{NMR}$ spectra suggested the appearance of $-\mathrm{CH}_{2}-\mathrm{O}-\mathrm{P}$ at $3.66 \mathrm{ppm}$. DSC indicated that $T_{\mathrm{g}}$ was below room temperature. Compound 17 cast film exhibited high conductivity $\left(0.12 \mathrm{~S} \mathrm{~cm}^{-1}, 85{ }^{\circ} \mathrm{C}\right)$ under $95 \%$ relative humidity. Compound $\mathbf{1 7}$ showed its possible application in fuel cells because of this excellent proton conductivity under humid conditions as well as high thermal stability. Another phosphorus-containing B-POSS used as flame-retardant material was reported by 
Song et al. [99]. Novel silicon-phosphorus linear polymers were synthesized via hydrosilylation reaction between B-POSS and 9,10-dihydro-9-oxa-10-phosphaphenanthrene-10-oxide derivatives. Then, different contents of B-POSS were blended with polycarbonate/acrylonitric-butadiene-styrene (PC/ABS) to study the flame-retardant properties. The temperature of $5 \mathrm{wt} \%$ weight loss $\left(T_{5 \%}\right)$ and the char residue yield at $800{ }^{\circ} \mathrm{C}$ suggested good flame retardancy of PC/ABS containing B-POSS.

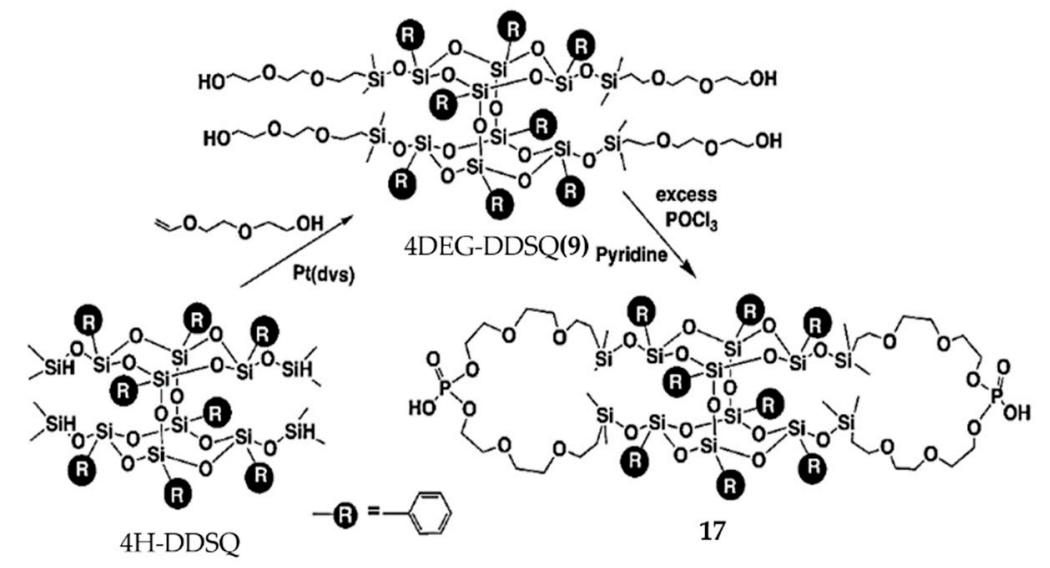

Figure 12. Synthesis of phosphonic-acid-containing B-POSS (PHOS-B-POSS) (17). (Reproduced with permission from Kucuk et al. [98]. Copyright 2012 Royal Society of Chemistry).

With a special substituted difluorosilane as a precursor, Tanaka et al. [100] reported a substituted difluorosilane prepared from the reaction between $\mathrm{BF}_{3} \cdot \mathrm{Et}_{2} \mathrm{O}$ and siloxanolate in the synthesis of an amide product. The difluorosilane, bearing a vinyl- or $\mathrm{BF}_{3}$-complexed amino group, was used as the raw material to synthesize polycyclic silsesquioxanes under mild conditions. This general strategy enabled the synthesis of B-POSS where various functional groups could be introduced.

3,13-Diglycidyloxypropyloctaphenyl B-POSS (13) was synthesized by Wang et al. via a hydrosilylation reaction between 3,13-dihydrooctaphenyl B-POSS (2) and allyl glycidyl ether [101]. Based on compound 13, Zhang et al. [102] further incorporated this B-POSS macromer into polybenzoxazine (PBZ) to investigate the thermal and mechanical properties through dynamic mechanical thermal analysis (DMTA) and TGA. The $T_{\mathrm{g}}$ value was higher than the PBZ and increased with the increased content of di-functional POSS macromere. With various amounts of 3,13-diglycidyl B-POSS, the nanocomposites containing $30 \mathrm{wt} \%$ of POSS showed the highest $T_{\mathrm{g}}$ value. The $T_{\mathrm{d}}$ increased with the increased compound 13 content.

Mono- and poly-epoxy groups containing B-POSS were synthesized by Cao et al. [103]. Curing kinetics and the thermal and mechanical performance of epoxy resin with varying amounts of B-POSS loading ratios were studied. The mono B-POSS showed more flexible structure and a better toughening effect, while the branched poly B-POSS exhibited higher thermal resistance.

A class of B-POSS-functionalized di-nuclear alkynylplatinum (II) terpyridine complexes exhibiting stereoisomerism was reported by Au-Yeung et al. [104]. The cis- and trans-complex stereoisomers were separated by column chromatography and identified by X-ray crystallography. The cis-isomer showed that the two methyl groups located on the silicon atoms pointing in the same direction exhibited a small $\mathrm{C}-\mathrm{Si}-\mathrm{Si}-\mathrm{C}$ torsion angle of $13.71^{\circ}$, whereas the trans-configuration showed a torsion angle of $180^{\circ}$. The cis-isomer also exhibited significantly different aggregation behavior in $50 \%$ water-acetone mixture. In $60 \%$ water-acetone solution, the cis-form showed a morphological transformation into spheres with a diameter of about $90 \mathrm{~nm}$.

\section{Polymer Composites Containing B-POSS}

Linear polymers refer to molecular chains that are linear and irregular. Due to the simplicity of materials processing, good solubility, high chain regularity, and POSS content in the hybrids [89,105], 
more attention has been paid to B-POSS-containing linear composite materials because of the specific nanostructure, hydrophobic core, functionalization, flame retardance, optical transparency, and low thermal conductivity.

\subsection{PU-POSS}

In recent years, PU has been applied in various areas such as packaging, coatings, footwear, and consumer care products [106]. The applications have been extended to the biomedical field due to the biocompatibility of PUs [107]. Even the liquid crystalline PU (LCPU) field, when LCPU was incorporated into POSS, the LCPU/POSS hybrids could show high melting and isotropization temperatures along with the broadening phase transition effect due to the incorporation of POSS [108]. Although PUs have been used in many fields, they still have many limitations, such as poor thermal and moisture stability originating from urethane groups and low mechanical resistance due to the intrinsic hardness of the hard segments. Therefore, many efforts have been made to solve these problems. The incorporation of POSS could affect the microphase-separated morphology, dynamics of phase separation, and order development of PU with different annealing temperatures. At low temperature, the POSS could promote the phase separation; however, the phase separation would slow under the high temperature [109]. Structural and property modifications of linear PUs with POSS have attracted much attention [110-112].

Hebda et al. [113] reported PU hybrid foam (PUF), which was obtained by introducing with 0 to $15 \mathrm{wt} \%$ POSS chemically. The POSS moieties act as both pendant groups and cross-links. The incorporation of POSS leads to reduced porosity and increased hardness. The simulated physiological fluid (SBF) confirmed the material is bioactivity as well as the POSS used. Huang et al. [114] synthesized a series of hybrid PUs containing double-decker octaphenylsilsesquioxanetetraol $\left(\mathrm{DDT}_{8} \mathrm{OH}\right)$ and polyols through a one-step method. DMA analysis suggested that the enhanced $T_{\mathrm{g}}$ was due to the presence of B-POSS in the main chain. SEM images showed the presence of nano- and micro-sized B-POSS aggregates because of the heterogeneous dispersion of B-POSS in liner PU, which was further confirmed by the presence of a nanocrystalline phase of B-POSS by XRD analysis. The hydrophobicity and mechanical performance of the liner PU with B-POSS was obviously enhanced as well. Xu et al. [115] also investigated organic-inorganic polyurethanes with B-POSS, and found that the microphase separation of POSS was self-organized into spherical microdomains $10-50 \mathrm{~nm}$ in diameter. Raftopoulos et al. [116] reported the molecular dynamics and morphology of a polyurethane system with POSS through SEM, DSC, (thermally stimulated depolarization currents) (TSDC), and DMA. Different loadings of POSS in polyurethane resulted in different morphologies. The particles in the main chain had no influence on the time scale of segmental dynamics. The increase of $T_{\mathrm{g}}$ had no influence on the relaxation of $\alpha^{\prime}$. The incorporation of POSS in the polyurethane structure affected the glass transition, the crystallinity of the soft phase, and the order-disorder transitions [117].

\subsection{Polyimide POSS}

Polyimides are high-performance materials that display many advanced properties, such as for instance good resistance at high temperature, low water absorption, and alkali resistance. Thus, they have been widely used in many fields such as microelectronics and the aerospace industry [118]. Many efforts have been made to improve the thermal and mechanical properties of polyimides containing POSS [101,119-129]. Wu et al. [130] synthesized a novel polyimide with B-POSS in the main chains (Figure 13). Different POSS content in the main chain was realized via a multi-step reaction methodology to obtain a series of linear semiaromatic sulfonated polyimides. The TGA data showed that the weight loss of linear sulfonated polyimide POSS (SPI-x-POSS) (x: mole ratio (\%) of phenylbisaniline-POSS) membranes was greatly increased by 200 to $450^{\circ} \mathrm{C}$. In addition, linear SPI-POSS copolymers displayed appreciable mechanical strength, good oxidative and hydrolytic stability, low methanol permeability, and high proton conductivity. Linear SPI-POSS-based copolymers were good potential candidates to fabricate proton exchange membrane (PEM) materials. 

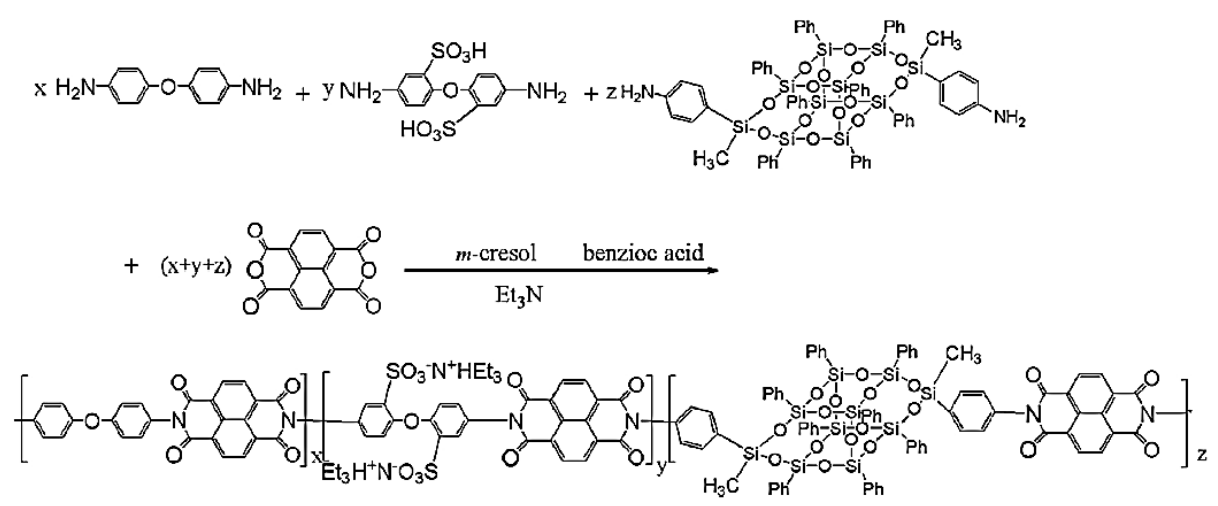

Figure 13. Synthesis of POSS-containing sulfonated polyimide in the main chain. (Reproduced with permission from Wu et al. [130]. Copyright 2015 Elsevier).

Liu et al. [68] synthesized a well-defined 3,13-dianilino B-POSS through the Heck reaction. The organic-inorganic polyimides prepared with 3,13-dianilino B-POSS displayed enhanced surface hydrophobicity compared to plain polyimide. The contact angle tested by water was increased by $20^{\circ}$ with $19.4 \mathrm{wt} \%$ B-POSS, whereas plain polyimide was $87^{\circ}$. Dielectric measurement showed that dielectric constants were significantly lower and decreased with the increased content of compound 4 .

\section{Conclusions}

This review focuses on the functional methods of bifunctional POSS and composites with B-POSS in the main chain. B-POSS has great prospects for the development of large numbers of groups in organic-inorganic hybrid copolymers with B-POSS as the main component. Therefore, a number of breakthrough studies were done on the structures and properties of hybrid materials with B-POSS. Nanocomposites with excellent properties were constructed with the incorporation of POSS into linear polymers. Good thermal stability and mechanical properties and exceptional dielectric properties and solubility were reported through this modification. Moreover, in the future, POSS-containing monomers will be applied in various fields that require outstanding properties of polymers. Without a doubt, many exciting developments await POSS-containing hybrid materials, with the possibility for exciting new discoveries in the future.

Author Contributions: Funding acquisition, H.C.; Resources: J.K.S. and M.W.; Supervision, H.C.; Writing—original draft, H.C. and M.W.; Writing—review and editing, H.C. and F.W.

Funding: This work was financially supported by the National Natural Science Foundation of China (grant no. 51702178), the International Cooperation Research Special Fund Project of Qilu University of Technology (QLUTGJHZ2018001), Youth Ph.D. Cooperation Funding of Shandong Academy of Sciences (2018BSHZ007), and the Program for Scientific Research Innovation Team in Colleges and Universities of Shandong Province.

Conflicts of Interest: The authors declare no conflict of interest.

\section{References}

1. Qiu, S.; Ma, C.; Wang, X.; Zhou, X.; Feng, X.; Yuen, R.K.; Hu, Y.J. Melamine-containing polyphosphazene wrapped ammonium polyphosphate: A novel multifunctional organic-inorganic hybrid flame retardant. J. Hazard. Mater. 2018, 344, 839-848. [CrossRef] [PubMed]

2. Abdollahi, A.; Roghani-Mamaqani, H.; Salami-Kalajahi, M.; Mousavi, A.; Razavi, B.; Shahi, S. Preparation of organic-inorganic hybrid nanocomposites from chemically modified epoxy and novolac resins and silica-attached carbon nanotubes by sol-gel process: Investigation of thermal degradation and stability. Prog. Org. Coat. 2018, 117, 154-165. [CrossRef]

3. Wan, C.; Tian, R.; Kondou, M.; Yang, R.; Zong, P.; Koumoto, K. Ultrahigh thermoelectric power factor in flexible hybrid inorganic-organic superlattice. Nat. Commun. 2017, 8, 1024. [CrossRef] [PubMed] 
4. Toshima, N.; Oshima, K.; Anno, H.; Nishinaka, T.; Ichikawa, S.; Iwata, A.; Shiraishi, Y. Novel hybrid organic thermoelectric materials: Three-component hybrid films consisting of a nanoparticle polymer complex, carbon nanotubes, and vinyl polymer. Adv. Mater. 2015, 27, 2246-2251. [CrossRef] [PubMed]

5. Genovese, M.; Lian, K. Polyoxometalate modified inorganic-organic nanocomposite materials for energy storage applications: A review. Curr. Opin. Solid State Mater. Sci. 2015, 19, 126-137. [CrossRef]

6. Shams, A.; Mirbagheri, S.A.; Jahani, Y. The synergistic effect of graphene oxide and POSS in mixed matrix membranes for desalination. Desalination 2019, 472, 114131. [CrossRef]

7. Nezakati, T.; Tan, A.; Lim, J.; Cormia, R.D.; Teoh, S.-H.; Seifalian, A.M. Ultra-low percolation threshold POSS-PCL/graphene electrically conductive polymer: Neural tissue engineering nanocomposites for neurosurgery. Mater. Sci. Eng. C 2019, 109915. [CrossRef]

8. Joseph, A.M.; Nagendra, B.; Surendran, K.; Gowd, E.B. Sustainable in Situ Approach to Covalently Functionalize Graphene Oxide with POSS Molecules Possessing Extremely Low Dielectric Behavior. Langmuir 2019, 35, 4672-4681. [CrossRef]

9. Raimondo, M.; Guadagno, L.; Speranza, V.; Bonnaud, L.; Dubois, P.; Lafdi, K. Multifunctional graphene/POSS epoxy resin tailored for aircraft lightning strike protection. Compos. Part B Eng. 2018, 140, 44-56. [CrossRef]

10. Tong, C.; McCarthy, S.; Li, Z.; Guo, J.; Li, Q.; Pacheco, C.N.; Ren, Y.; Allcock, H.R. Hybrid Polyphosphazene-organosilicon Polymers as Useful Elastomers. ACS Appl. Polym. Mater. 2019, 1881-1886. [CrossRef]

11. Kip, C.; Liu, S.; Fu, X.; Tuncel, A.; Lämmerhofer, M. In-situ photopolymerized C4-functionalized organosilicon monoliths for reversed-phase protein separation in nano-liquid chromatography. Talanta 2019, 198, 330-336. [CrossRef] [PubMed]

12. Demir, C.; Kip, Ç.; Tuncel, A. Alkanethiol-functionalized organosilicon monoliths for nano-reversed-phase liquid chromatography. Electrophoresis 2018, 39, 2919-2928. [CrossRef] [PubMed]

13. Soldatov, M.A.; Liu, H. POSS-phosphazene based porous material for adsorption of metal ions from water. Chem. Asian. J. 2019, 14, 4345-4351. [CrossRef] [PubMed]

14. Ciesielczyk, F.; Szwarc-Rzepka, K.; Przybysz, M.; Czech-Polak, J.; Heneczkowski, M.; Oleksy, M.; Jesionowski, T. Comprehensive characteristic and potential application of POSS-coated MgO-SiO2 binary oxide system. Colloids Surf. Physicochem. Eng. Asp. 2018, 537, 557-565. [CrossRef]

15. Liu, Z.; Ma, S.; Chen, L.; Xu, J.; Frontiers, M. Porous styryl-linked polyhedral oligomeric silsesquioxane (POSS) polymers used as support for platinum catalyst. Mater. Chem. Front. 2019, 3, 851-859. [CrossRef]

16. Lisuzzo, L.; Cavallaro, G.; Milioto, S.; Chemistry, G. Layered composite based on halloysite and natural polymers: A carrier for the $\mathrm{pH}$ controlled release of drugs. New J. Chem. 2019, 43, 10887-10893. [CrossRef]

17. Zhao, L.; Li, J.; Li, Z.; Zhang, Y.; Liao, S.; Yu, R.; Hui, D. Morphology and thermomechanical properties of natural rubber vulcanizates containing octavinyl polyhedral oligomeric silsesquioxane. Compos. Part B Eng. 2018, 139, 40-46. [CrossRef]

18. Dudziec, B.; Marciniec, B. Double-decker silsesquioxanes: Current chemistry and applications. Curr. Org. Chem. 2017, 21, 2794-2813. [CrossRef]

19. Blanco, I.; Bottino, F.A.; Abate, L. Influence of n-alkyl substituents on the thermal behaviour of Polyhedral Oligomeric Silsesquioxanes (POSSs) with different cage's periphery. Thermochim. Acta 2016, 623, 50-57. [CrossRef]

20. Fina, A.; Tabuani, D.; Carniato, F.; Frache, A.; Boccaleri, E.; Camino, G. Polyhedral Oligomeric Silsesquioxanes (POSS) thermal degradation. Thermochim. Acta 2006, 440, 36-42. [CrossRef]

21. Araki, H.; Naka, K. Synthesis and properties of star- and dumbbell-shaped POSS derivatives containing isobutyl groups. Polym. J. 2012, 44, 340-346. [CrossRef]

22. Dintcheva, N.T.; Morici, E.; Arrigo, R.; La Mantia, F.P. Interaction in POSS-poly(ethylene-co-acrylic acid) nanocomposites. Polym. J. 2014, 46, 160-166. [CrossRef]

23. Gu, J.; Li, Y.; Liang, C.; Tang, Y.; Tang, L.; Zhang, Y.; Kong, J.; Liu, H.; Guo, Z. Synchronously improved dielectric and mechanical properties of wave-transparent laminated composites combined with outstanding thermal stability by incorporating iysozyme/POSS functionalized PBO fibers. J. Mater. Chem. C 2018, 6, 7652-7660. [CrossRef]

24. David, E.; Andritsch, T. Dielectric Properties of Epoxy/POSS and PE/POSS Systems In Polymer/POSS Nanocomposites and Hybrid Materials. Springer 2018, 233-254. [CrossRef] 
25. Rüttiger, C.; Vowinkel, S.; Herzog, N.; Hofmann, K.; Ionescu, E.; Gallei, M. POSS-Containing Polymethacrylates on Cellulose-Based Substrates: Immobilization and Ceramic Formation. Coatings 2018, 8, 446. [CrossRef]

26. Akbari, A.; Naderahmadian, A.; Eftekhari-Sis, B. Silver and copper nanoparticles stabilized on ionic liquids-functionalized polyhedral oligomeric silsesquioxane (POSS): Highly active and recyclable hybrid catalysts. Polyhedron 2019, 171, 228-236. [CrossRef]

27. Mishra, K.; Gidley, D.; Singh, R.P. Influence of self-assembled compliant domains on the polymer network and mechanical properties of POSS-epoxy nanocomposites under cryogenic conditions. Eur. Polym. J. 2019, 116, 283-290. [CrossRef]

28. Chen, J.; Shan, J.; Xu, Y.; Su, P.; Tong, L.; Yuwen, L.; Weng, L.; Bao, B.; Wang, L. Polyhedral Oligomeric Silsesquioxane (POSS)-Based Cationic Conjugated Oligoelectrolyte/Porphyrin for Efficient Energy Transfer and Multiamplified Antimicrobial Activity. ACS Appl. Mater. Inter. 2018, 10, 34455-34463. [CrossRef]

29. Ye, Y.; Zhang, D.; Liu, T.; Liu, Z.; Liu, W.; Pu, J.; Chen, H.; Zhao, H.; Li, X. Improvement of anticorrosion ability of epoxy matrix in simulate marine environment by filled with superhydrophobic POSS-GO nanosheets. J. Hazard. Mater. 2019, 364, 244-255. [CrossRef]

30. Wang, C.; Gu, P.; Hu, B.; Zhang, Q. Recent progress in organic resistance memory with small molecules and inorganic-organic hybrid polymers as active elements. J. Mater. Chem. C 2015, 3, 10055-10065. [CrossRef]

31. Teng, Z.; Wang, B.; Hu, Y.; Xu, D. Light-responsive nanocomposites combining graphene oxide with POSS based on host-guest chemistry. Chin. Chem. Lett. 2019, 30, 717-720. [CrossRef]

32. Behera, P.K.; Mondal, P.; Singha, N.K. Self-Healable and Ultrahydrophobic Polyurethane-POSS Hybrids by Diels-Alder "Click" Reaction: A New Class of Coating Material. Macromolecules 2018, 51, 4770-4781. [CrossRef]

33. Kim, S.-W.; Choi, S.-Y.; Rhee, H.-W. Sulfonated poly (etheretherketone) based nanocomposite membranes containing POSS-SA for polymer electrolyte membrane fuel cells (PEMFC). J. Membr. Sci. 2018, 566, 69-76. [CrossRef]

34. Liu, N.; Du, Q.; Yin, G.; Liu, P.; Li, L.; Xie, H.; Zhu, C.; Li, Y.; Zhou, H.; Zhang, W.-B. Extremely low trap-state energy level perovskite solar cells passivated using NH 2-POSS with improved efficiency and stability. J. Mater. Chem. A 2018, 6, 6806-6814. [CrossRef]

35. Kajetanowicz, A.; Czaban, J.; Krishnan, G.R.; Malińska, M.; Woźniak, K.; Siddique, H.; Grela, K. Batchwise and Continuous Nanofiltration of POSS-Tagged Grubbs-Hoveyda-Type Olefin Metathesis Catalysts. Chem. Sus. Chem. 2013, 6, 182-192. [CrossRef]

36. Calabrese, C.; Liotta, L.F.; Giacalone, F.; Gruttadauria, M.; Aprile, C. Supported Polyhedral Oligomeric Silsesquioxane-Based (POSS) Materials as Highly Active Organocatalysts for the Conversion of $\mathrm{CO}_{2}$. ChemCatChem 2019, 11, 560-567. [CrossRef]

37. Nakamura, R.; Narikiyo, H.; Gon, M.; Tanaka, K.; Chujo, Y. An optical sensor for discriminating the chemical compositions and sizes of plastic particles in water based on water-soluble networks consisting of polyhedral oligomeric silsesquioxane presenting dual-color luminescence. Mater. Chem. Front. 2019, 3, 2690-2695. [CrossRef]

38. Sharma, A.K.; Hassan, M.K.; Tu, J.; Mauritz, K.A.; Wiggins, J. Kinetic studies of POSS-DGEBA precursors derived from monoamine functional POSS using dynamic dielectric sensing and nuclear magnetic resonance. J. Appl. Poly. Sci. 2018, 135, 45994. [CrossRef]

39. Lee, Y.-J.; Kim, J.-G.; Kim, J.-H.; Yun, J.; Jang, W.J. Detection of Dimethyl Methylphosphonate (DMMP) Using Polyhedral Oligomeric Silsesquioxane (POSS). J. Nanosci. Nanotechnol. 2018, 18, 6565-6569. [CrossRef]

40. Wang, Y.; Kalytchuk, S.; Wang, L.; Zhovtiuk, O.; Cepe, K.; Zboril, R.; Rogach, A. Carbon dot hybrids with oligomeric silsesquioxane: Solid-state luminophores with high photoluminescence quantum yield and applicability in white light emitting devices. Chem. Commun. 2015, 51, 2950-2953. [CrossRef]

41. Ghanbari, H.; Cousins, B.G.; Seifalian, A.M. A nanocage for nanomedicine: Polyhedral oligomeric silsesquioxane (POSS). Macromol. Rapid Commun. 2011, 32, 1032-1046. [CrossRef] [PubMed]

42. Ghanbari, H.; de Mel, A.; Seifalian, A.M. Cardiovascular application of polyhedral oligomeric silsesquioxane nanomaterials: A glimpse into prospective horizons. Int. J. Nanomed. 2011, 6, 775-786. [CrossRef]

43. Moszner, N.; Salz, U. Recent Developments of New Components for Dental Adhesives and Composites. Macromol. Mater. Eng. 2007, 292, 245-271. [CrossRef]

44. Blanco, I. Polyhedral oligomeric silsesquioxanes (POSS)s in medicine. J. Nanomed. 2018, 1, 1002. [CrossRef] 
45. Blanco, I. The Rediscovery of POSS: A Molecule Rather than a Filler. Polymers 2018, 10, 904. [CrossRef] [PubMed]

46. Raftopoulos, K.N.; Pielichowski, K. Segmental dynamics in hybrid polymer/POSS nanomaterials. Prog. Polym. Sci. 2016, 52, 136-187. [CrossRef]

47. Li, S.-N.; Li, B.; Gong, L.-X.; Yu, Z.-R.; Feng, Y.; Jia, D.; Zhou, Y.; Tang, L.-C. Design Enhanced mechanical properties of polyacrylamide/chitosan hydrogels by tuning the molecular structure of hyperbranched polysiloxane. Mater. Des. 2019, 162, 162-170. [CrossRef]

48. Rahmani, B.; Tzamtzis, S.; Ghanbari, H.; Burriesci, G.; Seifalian, A.M. Manufacturing and hydrodynamic assessment of a novel aortic valve made of a new nanocomposite polymer. J. Biomech. 2012, 45, 1205-1211. [CrossRef]

49. Prządka, D.; Jęczalik, J.; Andrzejewska, E.; Marciniec, B.; Dutkiewicz, M.; Szłapka, M.J.R.; Polymers, F. Novel hybrid polyurethane/POSS materials via bulk polymerization. React. Funct. Polym. 2013, 73, 114-121. [CrossRef]

50. Wei, K.; Li, L.; Zheng, S.; Wang, G.; Liang, Q. Organic-inorganic random copolymers from methacrylate-terminated poly(ethylene oxide) with 3-methacryloxypropylheptaphenyl polyhedral oligomeric silsesquioxane: Synthesis via RAFT polymerization and self-assembly behavior. Soft Matter 2014, 10, 383-394. [CrossRef]

51. Goffin, A.-L.; Duquesne, E.; Raquez, J.-M.; Miltner, H.E.; Ke, X.; Alexandre, M.; Van Tendeloo, G.; Van Mele, B.; Dubois, P. From polyester grafting onto POSS nanocage by ring-opening polymerization to high performance polyester/POSS nanocomposites. J. Mater. Chem. 2010, 20, 9415-9422. [CrossRef]

52. Phillips, S.H.; Haddad, T.S.; Tomczak, S.J. Developments in nanoscience: Polyhedral oligomeric silsesquioxane (POSS)-polymers. Curr. Opin. Solid State Mater. Sci. 2004, 8, 21-29. [CrossRef]

53. Watanabe, A.; Tadenuma, S.; Miyashita, T. Control of Refractive Index of Double-Decker-Shaped Polysilsesquioxane Film. J. Photopolym. Sci. Technol. 2008, 21, 317-318. [CrossRef]

54. Yoshida, K.; Hattori, T.; Ootake, N.; Tanaka, R.; Matsumoto, H. Silsesquioxane-Based Polymers: Synthesis of Phenylsilsesquioxanes with Double-Decker Structure and Their Polymers. Silicon Based Polym. 2008, 205-211. [CrossRef]

55. Aminuzzaman, M.; Watanabe, A.; Miyashita, T. Photochemical surface modification and characterization of double-decker-shaped polysilsesquioxane hybrid thin films. J. Mater. Chem. 2008, 18, 5092-5097. [CrossRef]

56. Aminuzzaman, M.; Watanabe, A.; Miyashita, T. Fabrication of conductive silver micropatterns on an organic-inorganic hybrid film by laser direct writing. Thin Solid Film. 2009, 517, 5935-5939. [CrossRef]

57. Devaux, E.; Rochery, M.; Bourbigot, S. Polyurethane/clay and polyurethane/POSS nanocomposites as flame retarded coating for polyester and cotton fabrics. Fire Mater. 2002, 26, 149-154. [CrossRef]

58. Gonzalez, R.I.; Phillips, S.H.; Hoflund, G.B. In Situ Oxygen-Atom Erosion Study of Polyhedral Oligomeric Silsesquioxane-Siloxane Copolymer. J. Spacecr. Rocket. 2000, 37, 463-467. [CrossRef]

59. Wright, M.E.; Schorzman, D.A.; Feher, F.J.; Jin, R.-Z. Synthesis and Thermal Curing of Aryl-Ethynyl-Terminated coPOSS Imide Oligomers: New Inorganic/Organic Hybrid Resins. Chem. Mater. 2003, 15, 264-268. [CrossRef]

60. Wei, K.; Wang, L.; Zheng, S. Organic-inorganic copolymers with double-decker silsesquioxane in the main chains by polymerization via click chemistry. J. Polym. Sci. Part A Polym. Chem. 2013, 51, 4221-4232. [CrossRef]

61. Kucuk, A.C.; Matsui, J.; Miyashita, T. Effects of subphase composition on the monolayer behavior of "core-coronae" type hybrid amphiphiles. Thin Solid Film. 2013, 534, 577-583. [CrossRef]

62. Seurer, B.; Vij, V.; Haddad, T.; Mabry, J.M.; Lee, A. Thermal Transitions and Reaction Kinetics of Polyhederal Silsesquioxane containing Phenylethynylphthalimides. Macromolecules 2010, 43, 9337-9347. [CrossRef]

63. Kohri, M.; Matsui, J.; Watanabe, A.; Miyashita, T. Synthesis and Optoelectronic Properties of Completely Carbazole-substituted Double-decker-shaped Silsesquioxane. Chem. Lett. 2010, 39, 1162-1163. [CrossRef]

64. Espinas, J.; Pelletier, J.D.A.; Abou-Hamad, E.; Emsley, L.; Basset, J.-M. A Silica-Supported Double-Decker Silsesquioxane Provides a Second Skin for the Selective Generation of Bipodal Surface Organometallic Complexes. Organometallics 2012, 31, 7610-7617. [CrossRef]

65. Zhang, W.; Xu, J.; Li, X.; Song, G.; Mu, J. Preparation, characterization, and properties of poly(aryl ether sulfone) systems with double-decker silsesquioxane in the main chains by reactive blending. J. Polym. Sci. Part A Polym. Chem. 2014, 52, 780-788. [CrossRef] 
66. Sodkhomkhum, R.; Ervithayasuporn, V. Synthesis of poly(siloxane/double-decker silsesquioxane) via dehydrocarbonative condensation reaction and its functionalization. Polymer 2016, 86, 113-119. [CrossRef]

67. Hoque, M.A.; Kawakami, Y. Synthesis of Polysilsesquioxanes with Double-Decker Silsesquioxane Repeating Units. J. Mater. Res. 2016, 10, 217-227. [CrossRef]

68. Liu, N.; Wei, K.; Wang, L.; Zheng, S. Organic-inorganic polyimides with double decker silsesquioxane in the main chains. Polym. Chem. 2016, 7, 1158-1167. [CrossRef]

69. Seino, M.; Hayakawa, T.; Ishida, Y.; Kakimoto, M.-A.; Watanabe, K.; Oikawa, H. Hydrosilylation Polymerization of Double-Decker-Shaped Silsesquioxane Having Hydrosilane with Diynes. Macromolecules 2006, 39, 3473-3475. [CrossRef]

70. Liu, N.; Li, L.; Wang, L.; Zheng, S. Organic-inorganic polybenzoxazine copolymers with double decker silsesquioxanes in the main chains: Synthesis and thermally activated ring-opening polymerization behavior. Polymer 2017, 109, 254-265. [CrossRef]

71. Wu, S.; Hayakawa, T.; Kakimoto, M.-A.; Oikawa, H. Synthesis and Characterization of Organosoluble Aromatic Polyimides Containing POSS in Main Chain Derived from Double-Decker-Shaped Silsesquioxane. Macromolecules 2008, 41, 3481-3487. [CrossRef]

72. Wu, S.; Hayakawa, T.; Kikuchi, R.; Grunzinger, S.J.; Kakimoto, M.-A.; Oikawa, H. Synthesis and Characterization of Semiaromatic Polyimides Containing POSS in Main Chain Derived from Double-Decker-Shaped Silsesquioxane. Macromolecules 2007, 40, 5698-5705. [CrossRef]

73. Chen, W.-C.; Kuo, S.-W. Ortho-Imide and Allyl Groups Effect on Highly Thermally Stable Polybenzoxazine/Double-Decker-Shaped Polyhedral Silsesquioxane Hybrids. Macromolecules 2018, 51, 9602-9612. [CrossRef]

74. Blanco, I.; Bottino, F.A.; Cicala, G.; Cozzo, G.; Latteri, A.; Recca, A. Synthesis and thermal characterization of new dumbbell shaped POSS/PS nanocomposites: Influence of the symmetrical structure of the nanoparticles on the dispersion/aggregation in the polymer matrix. Polym. Compos. 2015, 36, 1394-1400. [CrossRef]

75. Chi, H.; Wang, M.; Xiao, Y.; Wang, F.; KS, J. Self-Assembly and Applications of Amphiphilic Hybrid POSS Copolymers. Molecules 2018, 23, 2481. [CrossRef]

76. Kucuk, A.C.; Matsui, J.; Miyashita, T. Langmuir-Blodgett films composed of amphiphilic double-decker shaped polyhedral oligomeric silsesquioxanes. J. Colloid Interf. Sci. 2011, 355, 106-114. [CrossRef]

77. Kucuk, A.C.; Matsui, J.; Miyashita, T. Effects of Hydrogen Bonding on the Monolayer Properties of Amphiphilic Double-Decker-Shaped Polyhedral Silsesquioxanes. Langmuir 2011, 27, 6381-6388. [CrossRef]

78. Wei, K.; Wang, L.; Zheng, S. Organic-inorganic polyurethanes with 3,13-dihydroxypropyloctaphenyl double-decker silsesquioxane chain extender. Polym. Chem. 2013, 4, 1491-1501. [CrossRef]

79. Wen, Y.; Jiang, P.; Haryono, A.; Zhang, P.; Zhang, L.; Wai, P.T.; Li, D.; Cao, Z.; Xu, J. Synthesis and properties of epoxy soybean oil-based polyurethanes modified by 3,13-dimethyhydroxysilyl double-decker phenylsilsesquioxane. Chem. Pap. 2018, 73, 747-756. [CrossRef]

80. Han, S.Y.; Wang, X.M.; Shao, Y.; Guo, Q.Y.; Li, Y.; Zhang, W.B. Janus POSS Based on Mixed [2:6] Octakis-Adduct Regioisomers. Chemistry 2016, 22, 6397-6403. [CrossRef]

81. Zhang, X.; Gong, T.; Chi, H.; Li, T. Nanostructured polyurethane perylene bisimide ester assemblies with tuneable morphology and enhanced stability. R. Soc. Open Sci. 2018, 5, 171686. [CrossRef] [PubMed]

82. Chi, H.; Lim, S.L.; Wang, F.; Wang, X.; He, C.; Chin, W.S. Pure Blue-Light Emissive Poly (oligofluorenes) with Bifunctional POSS in the Main Chain. Macromol. Rapid Commun. 2014, 35, 801-806. [CrossRef] [PubMed]

83. Zhang, X.; Chi, H.; Li, T.; Wang, F.; Chin, W.S.; Xu, J. Energy transfer along a sequence controlled hybrid polymer. J. Polym. Sci. Part A Polym. Chem. 2018, 56, 1225-1233. [CrossRef]

84. Blanco, I.; Abate, L.; Bottino, F.A. Mono substituted octaphenyl POSSs: The effects of substituents on thermal properties and solubility. Thermochim. Acta 2017, 655, 117-123. [CrossRef]

85. Huan Hu, J.M.; Xianli, L.X.; Qiangyin, Y.Q.; Lifan, F.L.; Xuelian Wei. Benzocyclobutene-functional Double-Decker Silsesquioxane: SelfAssembled Hybrid Resin for High-Performance Dielectric and LED Encapsulants. Polym. Chem. 2019, 10, 1-10. [CrossRef]

86. Liao, Y.-T.; Lin, Y.-C.; Kuo, S.-W. Highly Thermally Stable, Transparent, and Flexible Polybenzoxazine Nanocomposites by Combination of Double-Decker-Shaped Polyhedral Silsesquioxanes and Polydimethylsiloxane. Macromolecules 2017, 50, 5739-5747. [CrossRef]

87. Mituła, K.; Dudziec, B.; Marciniec, B. Synthesis of Dialkenyl-Substituted Double-Decker Silsesquioxanes as Precursors for Linear Copolymeric Systems. J. Inorg. Organomet. Polym. Mater. 2017, 28, 500-507. [CrossRef] 
88. Walczak, M.; Januszewski, R.; Majchrzak, M.; Kubicki, M.; Dudziec, B.; Marciniec, B. Unusual cis and trans architecture of dihydrofunctional double-decker shaped silsesquioxane and synthesis of its ethyl bridged $\pi$-conjugated arene derivatives. New J. Chem. 2017, 41, 3290-3296. [CrossRef]

89. Zak, P.; Dudziec, B.; Kubicki, M.; Marciniec, B. Silylative coupling versus metathesis-Efficient methods for the synthesis of difunctionalized double-decker silsesquioxane derivatives. Chem. Eur. J. 2014, 20, 9387-9393. [CrossRef]

90. Żak, P.; Dudziec, B.; Dutkiewicz, M.; Ludwiczak, M.; Marciniec, B.; Nowicki, M. A new class of stereoregular vinylene-arylene copolymers with double-decker silsesquioxane in the main chain. J. Polym. Sci. Polym. Chem. 2016, 54, 1044-1055. [CrossRef]

91. Groch, P.; Dziubek, K.; Czaja, K.; Białek, M.; Mituła, K.; Dudziec, B.; Marciniec, B. Synthesis and structural characterization of ethylene copolymers containing double-decker silsesquioxane as pendant groups and cross-linkage sites by coordinative copolymerization. Eur. Polym. J. 2018, 100, 187-199. [CrossRef]

92. Vogelsang, D.F.; Dannatt, J.E.; Maleczka, R.E.; Lee, A. Separation of asymmetrically capped double-decker silsesquioxanes mixtures. Polyhedron 2018, 155, 189-193. [CrossRef]

93. Barry, B.-D.; Dannatt, J.E.; King, A.K.; Lee, A.; Maleczka, R.E. A general diversity oriented synthesis of asymmetric double-decker shaped silsesquioxanes. Chem. Commun. 2019, 55, 8623-8626. [CrossRef] [PubMed]

94. Zak, P.; Delaude, L.; Dudziec, B.; Marciniec, B. N-Heterocyclic carbene-based ruthenium-hydride catalysts for the synthesis of unsymmetrically functionalized double-decker silsesquioxanes. Chem. Commun. 2018, 54, 4306-4309. [CrossRef] [PubMed]

95. Tian, K.; Luh, T.Y.; Wang, X.; Hao, C.; Yang, X.; Li, Z.; Lai, G. Caterpillar-shaped polysilsesquioxanes. Chem. Commun. 2019, 3, 1-3. [CrossRef] [PubMed]

96. Blanco, I.; Bottino, F.A.; Bottino, P. Influence of symmetry/asymmetry of the nanoparticles structure on the thermal stability of polyhedral oligomeric silsesquioxane/polystyrene nanocomposites. Polym. Compos. 2012, 33, 1903-1910. [CrossRef]

97. Tanaka, K.; Adachi, S.; Chujo, Y. Structure-property relationship of octa-substituted POSS in thermal and mechanical reinforcements of conventional polymers. J. Polym. Sci. Part A Polym. Chem. 2009, 47, 5690-5697. [CrossRef]

98. Kucuk, A.C.; Matsui, J.; Miyashita, T. Proton-conducting electrolyte film of double-decker-shaped polyhedral silsesquioxane containing covalently bonded phosphonic acid groups. J. Mater. Chem. 2012, 22, 3853-3858. [CrossRef]

99. Song, W.; Zhang, W.; Li, Y.; Ma, H.; Lin, T.; Lu, C.; Nie, J.; Yang, G.; Chen, Z. Construction of novel silicon-phosphorus linear polymers with DDSQ and DOPO derivatives for effective flame retardancy of PC/ABS. Fire Mater. 2019, 43, 685-693. [CrossRef]

100. Tanaka, T.; Hasegawa, Y.; Kawamori, T.; Kunthom, R.; Takeda, N.; Unno, M. Synthesis of Double-Decker Silsesquioxanes from Substituted Difluorosilane. Organometallics 2019, 38, 743-747. [CrossRef]

101. Wang, L.; Zhang, C.; Zheng, S. Organic-inorganic poly(hydroxyether of bisphenol A) copolymers with double-decker silsesquioxane in the main chains. J. Mater. Chem. 2011, 21, 19344-19352. [CrossRef]

102. Zhang, C.; Liu, N.; Li, L.; Wang, L.; Zheng, S. Polybenzoxazine nanocomposites containing 3,13-Diglycidyl double-decker silsesquioxane. Polym. Compos. 2015, 38, 827-836. [CrossRef]

103. Cao, J.; Fan, H.; Li, B.-G.; Zhu, S. Synthesis and evaluation of Double-Decker Silsesquioxanes as modifying agent for epoxy resin. Polymer 2017, 124, 157-167. [CrossRef]

104. Au-Yeung, H.L.; Leung, S.Y.; Yam, V.W. Supramolecular assemblies of dinuclear alkynylplatinum(ii) terpyridine complexes with double-decker silsesquioxane nano-cores: The role of isomerism in constructing nano-structures. Chem. Commun. 2018, 54, 4128-4131. [CrossRef] [PubMed]

105. Dudziec, B.; Rzonsowska, M.; Marciniec, B.; Brzakalski, D.; Wozniak, B. New mono- and diethynylsiloxysilsesquioxanes-Efficient procedures for their synthesis. Dalton Trans. 2014, 43, 13201-13207. [CrossRef] [PubMed]

106. Karthika, M.; Chi, H.; Li, T.; Wang, H.; Thomas, S. Super-hydrophobic graphene oxide-azobenzene hybrids for improved hydrophobicity of polyurethane. Compos. Part B Eng. 2019, 106978. [CrossRef]

107. Raftopoulos, K.N.; Łukaszewska, I.; Klonos, P.A.; Hebda, E.; Bukowczan, A.; Kyritsis, A.; Pielichowski, K. Molecular and charge mobility of a poloxamer in the bulk and as soft component in polyurethanes. Polymer 2019, 182, 121821. [CrossRef] 
108. Bukowczan, A.; Hebda, E.; Czajkowski, M.; Pielichowski, K. The Synthesis and Properties of Liquid Crystalline Polyurethanes, Chemically Modified by Polyhedral Oligomericsilsesquioxanes. Molecules 2019, 24, 4013. [CrossRef]

109. Szefer, E.; Stafin, K.; Leszczyńska, A.; Zając, P.; Hebda, E.; Raftopoulos, K.N.; Pielichowski, K. Morphology, dynamics, and order development in a thermoplastic polyurethane with melt blended POSS. J. Polym. Sci. Polym. Phys. 2019, 57, 1133-1142. [CrossRef]

110. Turri, S.; Levi, M. Structure, Dynamic Properties, and Surface Behavior of Nanostructured Ionomeric Polyurethanes from Reactive Polyhedral Oligomeric Silsesquioxanes. Macromolecules 2005, 38, 5569-5574. [CrossRef]

111. Liu, H.; Zheng, S. Polyurethane networks nanoreinforced by polyhedral oligomeric silsesquioxane. Macromol. Rapid Commun. 2005, 26, 196-200. [CrossRef]

112. Oaten, M.; Choudhury, N.R. Silsesquioxane-Urethane Hybrid for Thin Film Applications. Macromolecules 2005, 38, 6392-6401. [CrossRef]

113. Hebda, E.; Bukowczan, A.; Michałowski, S.; Wroński, S.; Urbaniak, P.; Kaczmarek, M.; Hutnik, E.; Romaniuk, A.; Wolun-Cholewa, M.; Pielichowski, K. Examining the influence of functionalized POSS on the structure and bioactivity of flexible polyurethane foams. Mater. Sci. Eng. 2020, 108, 110370. [CrossRef]

114. Huang, J.; Jiang, P.; Wen, Y.; Deng, J.; He, J. Soy-castor oil based polyurethanes with octaphenylsilsesquioxanetetraol double-decker silsesquioxane in the main chains. RSC Adv. 2016, 6, 69521-69529. [CrossRef]

115. Xu, S.; Zhao, B.; Wei, K.; Zheng, S. Organic-inorganic polyurethanes with double decker silsesquioxanes in the main chains: Morphologies, surface hydrophobicity, and shape memory properties. J. Polym. Sci. Polym. Phys. 2018, 56, 893-906. [CrossRef]

116. Raftopoulos, K.N.; Jancia, M.; Aravopoulou, D.; Hebda, E.; Pielichowski, K.; Pissis, P. POSS along the Hard Segments of Polyurethane. Phase Separation and Molecular Dynamics. Macromolecules 2013, 46, 7378-7386. [CrossRef]

117. Majka, T.M.; Raftopoulos, K.N.; Pielichowski, K. The influence of POSS nanoparticles on selected thermal properties of polyurethane-based hybrids. J. Therm. Anal. Calorim. 2017, 133, 289-301. [CrossRef]

118. Tan, X.; Rodrigue, D. A Review on Porous Polymeric Membrane Preparation. Part II: Production Techniques with Polyethylene, Polydimethylsiloxane, Polypropylene, Polyimide, and Polytetrafluoroethylene. Polymers 2019, 11, 1310. [CrossRef]

119. Ree, M. High performance polyimides for applications in microelectronics and flat panel displays. Macromole. Res. 2006, 14, 1-33. [CrossRef]

120. Huang, J.; Lim, P.C.; Shen, L.; Pallathadka, P.K.; Zeng, K.; He, C. Cubic silsesquioxane-polyimide nanocomposites with improved thermomechanical and dielectric properties. Acta Mater. 2005, 53, 2395-2404. [CrossRef]

121. Chen, Y.; Kang, E.-T. New approach to nanocomposites of polyimides containing polyhedral oligomeric silsesquioxane for dielectric applications. Mater. Lett. 2004, 58, 3716-3719. [CrossRef]

122. Lee, Y.-J.; Huang, J.-M.; Kuo, S.-W.; Chang, F.-C. Low-dielectric, nanoporous polyimide films prepared from PEO-POSS nanoparticles. Polymer 2005, 46, 10056-10065. [CrossRef]

123. Devaraju, S.; Vengatesan, M.R.; Selvi, M.; Kumar, A.A.; Alagar, M. Synthesis and characterization of bisphenol-A ether diamine-based polyimide POSS nanocomposites for low K dielectric and flame-retardant applications. High Perform. Polym. 2012, 24, 85-96. [CrossRef]

124. Wahab, M.A.; Mya, K.Y.; He, C. Synthesis, morphology, and properties of hydroxyl terminated-POSS/polyimide low-k nanocomposite films. J. Polym. Sci. Part A Polym. Chem. 2008, 46, 5887-5896. [CrossRef]

125. Lee, Y.-J.; Huang, J.-M.; Kuo, S.-W.; Lu, J.-S.; Chang, F.-C. Polyimide and polyhedral oligomeric silsesquioxane nanocomposites for low-dielectric applications. Polymer 2005, 46, 173-181. [CrossRef]

126. Huang, J.-C.; He, C.-B.; Xiao, Y.; Mya, K.Y.; Dai, J.; Siow, Y.P. Polyimide/POSS nanocomposites: Interfacial interaction, thermal properties and mechanical properties. Polymer 2003, 44, 4491-4499. [CrossRef]

127. Huang, J.; Xiao, Y.; Mya, K.Y.; Liu, X.; He, C.; Dai, J.; Siow, Y.P. Thermomechanical properties of polyimide-epoxy nanocomposites from cubic silsesquioxane epoxides. J. Mater. Chem. 2004, 14, 2858-2863. [CrossRef] 
128. Atar, N.; Grossman, E.; Gouzman, I.; Bolker, A.; Murray, V.J.; Marshall, B.C.; Qian, M.; Minton, T.K.; Hanein, Y. Atomic-Oxygen-Durable and Electrically-Conductive CNT-POSS-Polyimide Flexible Films for Space Applications. ACS Appl. Mater. Inter. 2015, 7, 12047-12056. [CrossRef]

129. Hoque, M.A.; Kakihana, Y.; Shinke, S.; Kawakami, Y. Polysiloxanes with Periodically Distributed Isomeric Double-Decker Silsesquioxane in the Main Chain. Macromolecules 2009, 42, 3309-3315. [CrossRef]

130. Wu, Z.; Zhang, S.; Li, H.; Liang, Y.; Qi, Z.; Xu, Y.; Tang, Y.; Gong, C. Linear sulfonated polyimides containing polyhedral oligomeric silsesquioxane (POSS) in main chain for proton exchange membranes. J. Power Sources 2015, 290, 42-52. [CrossRef]

(C) 2019 by the authors. Licensee MDPI, Basel, Switzerland. This article is an open access article distributed under the terms and conditions of the Creative Commons Attribution (CC BY) license (http://creativecommons.org/licenses/by/4.0/). 